\title{
Práticas de gestão de custos logísticos: Estudo de caso de uma empresa do setor alimentício
}

Practices of logistics costs management: case study in a food industry company

\section{Marcos Antonio Souza}

Doutor em Controladoria e Contabilidade pela Universidade de São Paulo

Professor do Mestrado em Ciências Contábeis da Universidade do Vale do Rio dos Sinos

Endereço: Avenida Unisinos, no 950 - Bairro Cristo Rei - Caixa Postal 275

Ciências Econômicas - Sala 5A402.a

CEP: 93022-000 - São Leopoldo/RS - Brasil

E-mail: marcosas@unisinos.br

Telefone: (51) 3037-1000 - Ramal 1580

\section{Carla Schnorr}

Mestre em Ciências Contábeis pela Universidade do Vale do Rio dos Sinos

Endereço: Rua Sergipe, no 203 - Bairro São Cristóvão

CEP: 95.900-000 - Lajeado/RS - Brasil

E-mail: carla@schnorr.com.br

Telefone: (51) 3714-5019

\section{Fernanda Baldasso Ferreira}

Mestre em Ciências Contábeis pela Universidade do Vale do Rio dos Sinos Auditora Interna da Gerdau S.A.

Endereço: Avenida Farrapos, no 1811, Bairro Floresta

CEP: 90220-005 - Porto Alegre/RS - Brasil

E-mail: febferreira@gmail.com

Telefone: (51) 9180-7511

Artigo recebido em 02/07/2011. Revisado por pares em 08/08/2012. Reformulado em 15/10/2012. Recomendado para publicação em 26/10/2012 por Sandra Rolim Ensslin (Editora Científica). Publicado em 30/04/2013. 


\title{
Resumo
}

O estudo identifica as práticas de gestão dos custos logísticos utilizadas por uma empresa do setor alimentício. É uma pesquisa descritiva e exploratória, realizada no último trimestre de 2010 sob a forma de estudo de caso único. A coleta de dados deu-se por pesquisa documental e entrevistas semiestruturadas com três gerentes e um consultor externo da empresa. $\mathrm{O}$ uso das práticas ocorre em menor nível do que define a literatura, mas há ações, por meio de investimentos em tecnologia e sistemas, para uso mais intensivo. Mesmo assim identifica-se mais aderência do que o identificado em outros estudos empíricos analisados.

Palavras-chave: Gestão Estratégica de Custos. Custos Logísticos. Cadeia de Suprimentos.

\begin{abstract}
The study identifies the practices to logistics costs management adopted by a food industry company. This is a descriptive and exploratory study conducted in the last quarter of 2010 as a single case study. Data collection was performed by documentary research and semistructured interviews with three company managers and an external consultant. The uses of the practices occur on the lower level that defines the literature, but there are actions, by investments in technology and in systems to increase the usage. Even so, there is more adherence than identified in other empirical studies analyzed.
\end{abstract}

Keywords: Strategic Cost Management. Logistics Costs. Supply Chain.

\section{Introdução}

As transformações no ambiente operacional das empresas, as mudanças econômicas impulsionadas pela globalização e os avanços tecnológicos fizeram com que as empresas direcionassem o foco da gestão estratégica para a melhoria dos seus processos funcionais. As empresas identificaram que, por meio da logística e do gerenciamento da cadeia de suprimentos, poderiam melhorar a eficiência e eficácia organizacional. LaLonde e Pohlen (1996) destacam que, em decorrência da importância dos processos logísticos nas operações, as práticas de análise de custos também passaram por um processo de evolução e adaptação a fim de permitir melhor compreensão e gestão dos custos logísticos. Esse entendimento tem sido corroborado por estudos mais recentes, como o de Somuyiwa (2010) que utiliza o total cost model para estruturar um sistema de mensuração de custos logísticos.

Sob um olhar específico na indústria de alimentos, a logística tem um enfoque de manutenção da qualidade dos produtos e de acondicionamento especial durante o processo de produção, armazenagem e distribuição. Isso é reconhecido por Laidens, Teles e Müller (2007), Guerreiro, Bio e Merschmann (2008), Wang, Gao e Lin (2010) e Vodenicharova (2011), para os quais, nesse setor, existem influências de aspectos particulares que acabam por aumentar ainda mais a importância das atividades logísticas no negócio. Como consequência, o conhecimento sobre custos logísticos nessa indústria tornou-se cada vez mais relevante para a competitividade das empresas. Dada a evolução desses conceitos, o desafio 
enfrentado reside na implantação de práticas de gestão que possibilitem a mensuração dos custos logísticos, gerando informações que expressem a realidade das atividades da organização.

É desse contexto que emerge o objetivo deste estudo, ou seja, identificar o uso de práticas de gestão dos custos logísticos por uma empresa do setor alimentício. Com base nessa identificação, é possível qualificar o grau de adesão e validação dada pela empresa àquelas práticas desenvolvidas e defendidas pela literatura. No caso deste estudo, trata-se da realidade de organização que atua em mercado de baixa concorrência, mas com foco no aumento da lucratividade e na manutenção de níveis de serviços adequados às solicitações dos clientes. A utilização da empresa como base para desenvolvimento do estudo se justifica pelos seguintes argumentos: (1) o segmento de atuação, alimentício, não muito explorado nesse tipo de estudo; (2) representatividade econômica e social regional; (3) iniciativas próprias para mensuração dos custos logísticos; (4) fase de transição para um sistema integrado de mensuração das atividades logísticas; e, (5) disponibilidade e acessibilidade aos dados e informações correspondentes.

A utilidade desses estudos também é referendada por Iudícibus (1996), que destaca a necessidade de pesquisas sobre a teoria realizadas com a colaboração das empresas. Esse estudo surge também em complemento a diversos outros realizados sobre o tema, os quais enfatizam a relevância e as contribuições das práticas de gestão dos custos logísticos, destacando-se Gonzáles (2002), Lima (2002), Souza, Collaziol e Kirch (2004), Kaminski (2004), Laidens, Teles e Müller (2007) e Souza et al. (2010).

O artigo está estruturado em cinco seções, começando com esta que trata da introdução do trabalho, seguida dos aportes teóricos na segunda seção. Na terceira seção, têmse os procedimentos metodológicos adotados na pesquisa; nas duas seções seguintes, há a análise dos dados e as conclusões do estudo. A lista das referências completa o conteúdo.

\section{Referencial Teórico}

\subsection{A Estratégica Corporativa e a Vantagem Competitiva}

Para Mintzberg et al. (2006), a estratégia pode ser definida como um padrão, ou um plano, que define as principais metas, políticas e sequências de ações futuras da organização em um todo equilibrado e coeso. Dentre os níveis estratégicos de Wheelwright (1984), há a estratégia funcional, que é ligada às diversas áreas da unidade estratégica de negócios, como produção, logística, marketing e finanças.

Paiva, Carvalho Jr. e Fensterseifer (2009) destacam que as estratégias funcionais são desenvolvidas com o objetivo de amparar as estratégias de negócios e definir como irá ocorrer o relacionamento entre essas funções. Skinner (1969) e Wheelwright (1984) explicam que o principal ponto é a manutenção da complementaridade entre as estratégias. Dentre os principais processos funcionais estratégicos citados pelos autores, há destaque para a logística.

A logística e o gerenciamento da cadeia de suprimentos têm obtido relevância cada vez maior no alcance da eficácia organizacional, no aumento da lucratividade e na sustentabilidade das posições conquistadas em termos de competitividade. Com base em Porter (1989) e Christopher (2007), são apresentadas, no Quadro 1, algumas ações relacionadas ao gerenciamento logístico, suporte da busca pela vantagem competitiva. 
Quadro 1 - Vantagem competitiva e gerenciamento logístico

\begin{tabular}{|c|c|c|}
\hline Vantagem Competitiva & \multicolumn{1}{|c|}{ Ações Decorrentes do Gerenciamento Logístico } \\
\hline $\begin{array}{c}\text { Vantagem em } \\
\text { diferenciação: }\end{array}$ & - $\begin{array}{l}\text { Promover serviços personalizados aos clientes, por meio de políticas de } \\
\text { entregas diferenciadas com canais de distribuição de acordo com as } \\
\text { exigências dos clientes. }\end{array}$ \\
$\begin{array}{c}\text { Significa criar uma } \\
\text { singularidade para o } \\
\text { produto, visando atender } \\
\text { clientes com necessidades }\end{array}$ & $\begin{array}{l}\text { Aprimorar o relacionamento com os clientes a fim de entender e satisfazer } \\
\text { as suas necessidades, proporcionando canais eficientes de comunicação. } \\
\text { específicas. }\end{array}$ & $\begin{array}{l}\text { Melhorar o desempenho com relação aos fornecedores, desenvolvendo } \\
\text { inovações e serviços mais eficazes. }\end{array}$ \\
\hline $\begin{array}{c}\text { Vantagem em custos: } \\
\text { Foco constante na redução } \\
\text { de custos, resultando em } \\
\text { preço de venda menor que } \\
\text { o dos concorrentes, sem } \\
\text { redução da lucratividade e } \\
\text { da qualidade do serviço. }\end{array}$ & $\begin{array}{l}\text { Elevar a produtividade por meio de ações de suporte à produção com uma } \\
\text { logística interna eficiente e adequada; Melhorar a utilização da capacidade } \\
\text { produtiva. }\end{array}$ \\
Reduzir estoques, por meio de um adequado planejamento de produção e de \\
canais de comunicação eficientes com fornecedores e clientes. \\
Promover maior integração com cliente e fornecedores por meio de sistemas \\
que possibilitem um fluxo de informações com vistas ao reabastecimento \\
contínuo.
\end{tabular}

Fonte: Adaptado de Porter (1989) e Christopher (2007).

Verifica-se, segundo os autores citados, que a inclusão da logística na gestão estratégica contribui para a obtenção da vantagem competitiva, seja o foco estratégico da empresa a liderança por diferenciação ou por custos.

De outra parte e apesar dessa vinculação com estratégia empresarial e vantagem competitiva, o entendimento de Souza, Collaziol e Kirsh (2004) é que a logística, a exemplo de outras práticas operacionais, tornou-se um pré-requisito às empresas que almejam manterse no mercado de forma estável.

\subsection{A Logística e a Cadeia de Suprimentos}

Dentre as várias abordagens sobre o início da logística, Wood Jr. e Zuffo (1998) enfatizam que ele ocorreu no século XX, no momento em que a preocupação central era com questões de transporte para o escoamento da produção agrícola. Da década de 1940 até o início da de 1960, o processo logístico voltou-se para a identificação dos aspectos da eficiência no fluxo de materiais, tais como a gestão de estoques, compras, armazenagem e transporte.

Após uma década, iniciou-se a visão integrada da logística, com o foco em aspectos como custo total e o entendimento dos sistemas de informações e mensuração desses custos. No início da década de 1970, correspondente à era do 'foco no cliente', teve-se a ênfase na aplicação de métodos relacionados à produtividade logística. E nas décadas de 1980 a 2000, o foco passa para a gestão total da cadeia de suprimentos (Supply Chain Management - SCM), sempre com o objetivo de atender às necessidades dos clientes (WOOD JR.; ZUFFO, 1998).

Nessa fase do $S C M$, ganham força os conceitos de logística reversa e o Enterprise Consumer Response (ECR). O primeiro diz respeito ao fluxo de materiais que voltam à empresa por algum motivo devoluções de clientes, retorno de embalagens, retorno de produtos e/ou materiais para atender à legislação ou para a reutilização de partes dos produtos que podem trazer benefícios econômicos para a empresa. Já o ECR trata da performance de processos e serviços oferecidos aos clientes, visando melhorar a resposta da empresa a eles.

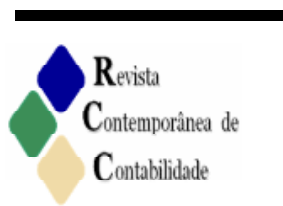


A partir da década de 2000, tem-se a formação de alianças de empresas, visando à execução conjunta de determinados processos. Há também a abertura para novos canais de distribuição, como a utilização do comércio eletrônico pela internet (SOUZA, 2002).

O Quadro 2 ilustra a evolução histórica do conceito de logística, assim como o aumento da sua importância do contex to empresarial.

Quadro 2 - Evolução da Logística

\begin{tabular}{|c|c|c|c|c|c|}
\hline Fases & $1900-1940$ & 1940 - 1960 & 1960 - 1980 & $1980-2000$ & 2000 - atual \\
\hline $\begin{array}{l}\text { Perspectiva } \\
\text { Dominante }\end{array}$ & Produção Agrícola & $\begin{array}{c}\text { Administração em } \\
\text { funções } \\
\text { segmentadas }\end{array}$ & Logística integrada & $\begin{array}{l}\text { Supply Chain } \\
\text { Management }\end{array}$ & $\begin{array}{l}\text { Gestão } \\
\text { Estratégica da } \\
\text { Logística }\end{array}$ \\
\hline Focos & $\begin{array}{l}\text { Transporte para } \\
\text { escoamento da } \\
\text { produção do } \\
\text { campo. }\end{array}$ & $\begin{array}{l}\text { Gestão de estoques. } \\
\text { Gestão de compras. } \\
\text { Gestão de } \\
\text { materiais. } \\
\text { Otimização dos } \\
\text { transportes. }\end{array}$ & $\begin{array}{l}\text { Visão Global do } \\
\text { Sistema na } \\
\text { Empresa, } \\
\text { integração dos } \\
\text { sistemas de } \\
\text { informação } \\
\text { existentes. }\end{array}$ & \begin{tabular}{|} 
Visão Global da \\
empresa com sua \\
cadeia de \\
suprimentos e seus \\
canais de \\
distribuição. \\
Logística reversa. \\
ECR.
\end{tabular} & $\begin{array}{c}\text { Ampla } \\
\text { utilização de } \\
\text { alianças } \\
\text { estratégicas, } \\
\text { co-makership, } \\
\text { subcontratados } \\
\text { e canais } \\
\text { alternativos de } \\
\text { distribuição. }\end{array}$ \\
\hline
\end{tabular}

Fonte: Wood Jr. e Zuffo (1998) e Souza (2002).

Para Ballou (2006a), o aspecto atual do pensamento da logística é o conceito do SCM, que define que os processos logísticos são responsáveis pelo fluxo de materiais em toda a cadeia e devem ser gerenciados para assegurar melhores resultados com a redução de desperdício e agregação de valor. Tal mudança aponta a gradativa preocupação pela redução dos custos operacionais, maior produtividade e elevação da exigência dos clientes, que podem ser obtidas pela eficiência logística (SILVA; VILLAR, 2007).

Lima (2002) destaca que um dos principais desafios da logística é o equilíbrio entre os custos e os níveis de serviços oferecidos aos clientes, o trade-off. Observa ainda que os clientes têm exigido melhores níveis de serviços e custos reduzidos, um processo impulsionado pela ampla abertura dos mercados, que aumenta a competitividade. Assim, é possível identificar a logística como uma ferramenta que integra toda a cadeia de suprimentos, que promove o planejamento e a coordenação do fluxo de materiais da fonte ao usuário final, e principalmente que agrega valor ao produto por meio do serviço prestado (LIMA, 2002).

Estrategicamente, pode-se dizer que as empresas buscam essas vantagens competitivas pela integração das especificidades da logística, tais como a de suprimentos, a de apoio à manufatura e a de distribuição física. A Figura 1 apresenta a visão integrada entre esses elementos e os elos participantes da cadeia de suprimentos (KAMINSKI, 2004).

Para Bowersox e Closs (1996), a função de suprimento, ou logística inbound, relaciona-se com as atividades de obtenção de materiais de fornecedores externos em tempo hábil e ao menor custo. Essa função é influenciada pela logística de apoio à manufatura.

A função de apoio à manufatura, a logística interna, relaciona-se com as atividades de apoio às operações de produção. Abrange as necessidades de movimentação de materiais, concentrando no gerenciamento de estoques das fases da produção (KAMINSKI, 2004). 
Figura 1 - Logística integrada e a cadeia de suprimentos

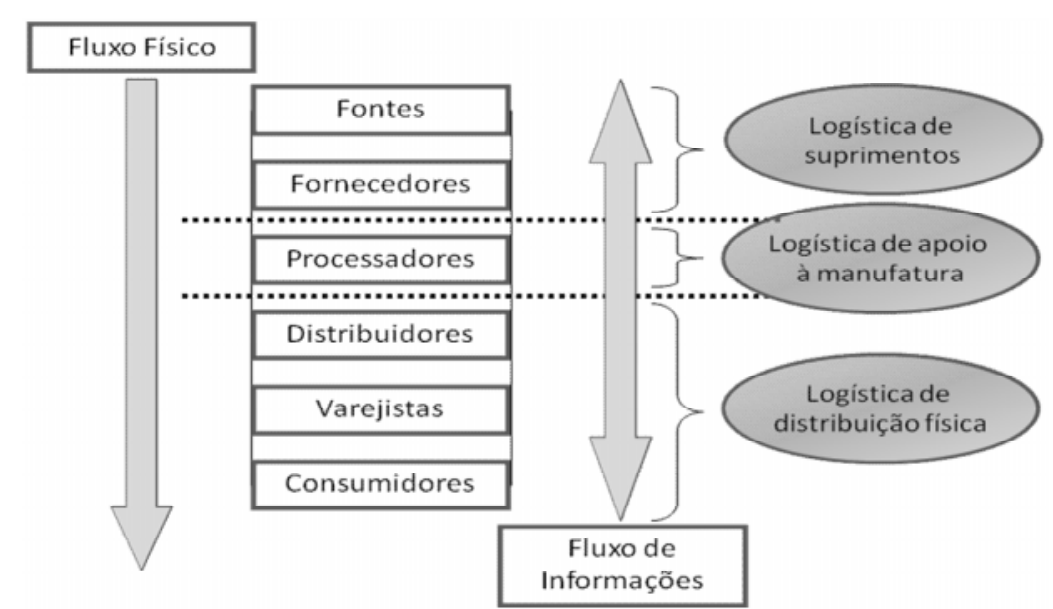

Fonte: Adaptado de Bowersox e Closs (1996).

Lima (2002) e Kaminski (2004) destacam que a função de distribuição física, a logística outbound, envolve as atividades associadas à coleta, ao armazenamento e à distribuição dos produtos para os clientes. Essas atividades estão relacionadas diretamente com as atividades de marketing, pois é o serviço da logística mais perceptível ao cliente.

Pode-se resumir, segundo Cooke (2006), que o desafio da logística está em gerenciar os seus três macroprocessos (suprimentos, manufatura e distribuição) de forma única, buscando ações que minimizem os custos finais, independente das divisões existentes.

\subsection{A Gestão dos Custos Logísticos}

A análise dos custos logísticos surge paralelamente à evolução do conceito de logística integrada. A expansão e diversificação das empresas em termos geográficos e o consequente crescimento dos custos logísticos enfatizaram a necessidade de um controle mais acurado para suportar análises de contribuição por produto, cliente, fornecedor e de possibilitar a escolha entre custos e níveis de serviços (LALONDE; POHLEN, 1996).

Para Freires (2000), os custos logísticos são aqueles relacionados às atividades de planejar, implantar e controlar todos os materiais e serviços de entrada, os materiais em processo e os produtos ou serviços de saída, desde o ponto de origem até o ponto de consumo, inclusive o processo de descarte.

Kaminski (2004) define que a gestão dos custos logísticos favorece a tomada de decisões tais como: correta alocação de recursos, controle de estoques, decisões sobre terceirização, gerenciamento do custo versus nível de serviço prestado, eliminação de gargalos, avaliação de desempenho do sistema e melhora nos processos. A respeito da eliminação de gargalos, referida por Kaminski (2004), cabe destacar a contribuição da teoria das restrições para os trabalhos da logística e na gestão dos custos decorrentes, conforme abordado por Souza e Pires (2010).

Os principais elementos de custos logísticos e os fatores que afetam a sua ocorrência estão descritos no Quadro 3. 


\begin{tabular}{|c|c|c|}
\hline \multicolumn{3}{|c|}{ Quadro 3 - Caracterização dos custos logísticos } \\
\hline Custos Logísticos & Fatores que afetam nos custos logísticos & Exemplos \\
\hline Níveis de serviço & $\begin{array}{l}\text { Os custos dos níveis de serviço representam aqueles } \\
\text { incorridos para atender aos níveis esperados pelos } \\
\text { clientes. A redução desses custos depende da gestão de } \\
\text { todos os outros elementos descritos neste quadro, de } \\
\text { forma conjunta. }\end{array}$ & $\begin{array}{l}\text { Os custos de implantação de } \\
\text { novos canais para atendimento } \\
\text { mais rápido, utilização da } \\
\text { internet para exposição de } \\
\text { produtos. }\end{array}$ \\
\hline Custos de lotes & $\begin{array}{l}\text { A definição do mix de produção impacta diretamente nos } \\
\text { custos de lotes. Quanto maior o mix, maior é o custo de } \\
\text { administração e de operacionalização dos lotes. }\end{array}$ & $\begin{array}{l}\text { Custo de setup de máquinas, } \\
\text { tempo de } \quad \text { parada, } \\
\text { movimentação, programação e } \\
\text { expedição. }\end{array}$ \\
\hline $\begin{array}{l}\text { Custos de } \\
\text { embalagem }\end{array}$ & $\begin{array}{l}\text { Relacionados ao acondicionamento necessário para o } \\
\text { produto e algumas vezes à diferenciação requisitada pelos } \\
\text { clientes, para armazenagem, transporte e manuseio. }\end{array}$ & $\begin{array}{l}\text { Custo de aquisição da } \\
\text { embalagem e da aplicação, } \\
\text { incluindo para transporte e } \\
\text { acondicionamento. }\end{array}$ \\
\hline $\begin{array}{c}\text { Custos de } \\
\text { armazenagem }\end{array}$ & $\begin{array}{l}\text { Dependem da centralização ou não da distribuição. } \\
\text { Quanto mais centros de distribuição existirem, maiores } \\
\text { serão os custos associados. Também está relacionado aos } \\
\text { níveis de inventário utilizados pela empresa; quanto } \\
\text { maiores mais armazéns devem ser considerados. }\end{array}$ & 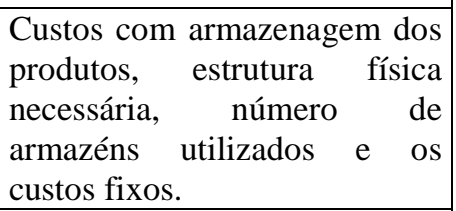 \\
\hline $\begin{array}{l}\text { Custos de } \\
\text { manutenção de } \\
\text { inventário }\end{array}$ & $\begin{array}{l}\text { Dependem, em grande parte, do planejamento e controle } \\
\text { da produção. O planejamento define como a demanda será } \\
\text { atendida; quanto melhor o planejamento menor a } \\
\text { necessidade de estoque. }\end{array}$ & $\begin{array}{l}\text { Custos com seguros, impostos, } \\
\text { avaria, roubo, obsolescência e } \\
\text { custo de oportunidade. }\end{array}$ \\
\hline $\begin{array}{l}\text { Custos de } \\
\text { processamento de } \\
\text { pedidos e de TI }\end{array}$ & $\begin{array}{l}\text { Tecnologia para o recebimento e processamento dos } \\
\text { pedidos de produção, além do tratamento das requisições } \\
\text { de insumos para a produção. Quando mais integrados os } \\
\text { sistemas (incluindo clientes e fornecedores), maior será a } \\
\text { produtividade dessas atividades. }\end{array}$ & 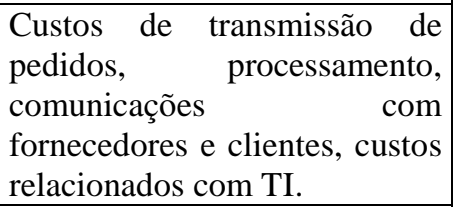 \\
\hline $\begin{array}{l}\text { Custos com } \\
\text { planejamento e } \\
\text { controle da } \\
\text { produção }\end{array}$ & $\begin{array}{l}\text { Utilização de sistemas de informação que considerem a } \\
\text { capacidade instalada, localização, níveis de estoque, etc., a } \\
\text { fim de adequar a sincronização das entradas (insumos) } \\
\text { com as saídas (produção). Quanto melhor o planejamento, } \\
\text { menos compras emergenciais e menor complexidade para } \\
\text { programação de produção. }\end{array}$ & $\begin{array}{l}\text { Custos com sistemas de } \\
\text { informação, custos com } \\
\text { pessoas capacitadas para a } \\
\text { realização do planejamento, } \\
\text { custos para implantação dos } \\
\text { controles. }\end{array}$ \\
\hline $\begin{array}{l}\text { Custos de } \\
\text { transportes }\end{array}$ & $\begin{array}{l}\text { Renovação da frota, distância dos fornecedores e clientes, } \\
\text { utilização de CD, de sistema de integração como o EDI } \\
\text { para otimização dos fretes. Relacionar produtos e } \\
\text { embalagem. }\end{array}$ & $\begin{array}{l}\text { Combustível, custos } \\
\text { manutenção da frota. }\end{array}$ \\
\hline $\begin{array}{l}\text { Custos da logística } \\
\text { reversa }\end{array}$ & $\begin{array}{l}\text { Relacionado ao processo de retorno de produtos vendidos, } \\
\text { seja pela obrigação legal, ou por questões de qualidade ou } \\
\text { até mesmo para reaproveitamento da empresa. A logística } \\
\text { reversa pode influenciar outros elementos como } \\
\text { transportes, inventário etc. }\end{array}$ & $\begin{array}{l}\text { Custos de transporte para } \\
\text { retorno dos produtos a serem } \\
\text { reutilizados, custos } r \text { de } \\
\text { armazenamento, custos de } \\
\text { limpeza dos materiais. }\end{array}$ \\
\hline
\end{tabular}

Fonte: Adaptado de Cavinato (1992), Faria e Robles (2000) e Daher, Silva e Fonseca (2006).

Lima (2002) considera que o sistema de gerenciamento dos custos logísticos pode ir além dos limites da empresa e considerar atividades desenvolvidas por outros componentes da cadeia de suprimentos. E isso se torna relevante no contexto atual, visto que muitos serviços que não fazem parte do core business da empresa passaram a ser terceirizados.

Cokins (2001) comenta que a dificuldade da gestão não está em medir a receita ou estabelecer metas, mas, sim, em medir e controlar os custos. O diferencial passa a ser a 
habilidade da administração em medir corretamente os custos e evidenciar as margens de contribuição que os produtos e serviços oferecem.

Para Lima (2002), parte dos problemas para analisar os custos é a utilização de informações contábeis como suporte às decisões. Salienta que o objetivo da contabilidade societária é atender à legislação e, como consequência, é limitada quando utilizada para fins de gestão. Uma das principais limitações é adotar um plano de contas que não possibilite a evidenciação específica dos custos logísticos, assim como um método de custeio inapropriado. Algumas práticas relacionadas a custos logísticos são discutidas na sequência.

Não obstante tais dificuldades e problemas, modelos de gestão de custos logísticos têm sido desenvolvidos. Wang Bo (2010) desenvolve seu modelo com base no objetivo de criar valor para a empresa, mais prioritário do que obter o menor custo. Há aqui o reconhecimento de que a redução de custos acima de determinado nível não é uma economia, mas, sim, a redução da capacidade de geração de valor. O modelo de Wang Bo (2010) utiliza quatro técnicas específicas: (1) o ABC (Activity Based Costing), para análise dos direcionadores; (2) o ABM (Activity Based Management), como padrões de controle; (3) o ME (Medidores Estratégicos); (4) EVA (Economic Value Added), como mensuração do valor.

Tem-se também o estudo de Lambert e Stock (2001), que apresenta críticas à gestão de custos quando efetuada de forma isolada, local, sem uma abordagem total. O modelo desenvolvido destaca que a redução de custo em uma área pode ser compensada desfavoravelmente pelo aumento dos custos em outras áreas. O modelo baseia-se, então, na utilização integrada dos cinco principais fatores geradores dos custos logísticos: custos com pedidos e sistema de informação; custos com a quantidade de lotes; custos de transporte; custos de armazenagem; e, custos de carregamento de estoques. Na essência, o modelo enseja a análise interdependente das operações e decisões.

\subsection{Práticas de Gestão dos Custos Logísticos}

A fim de estruturar um sistema de gerenciamento dos custos logísticos, o método de custeio $A B C$ e as técnicas de gestão operacional Total Cost of Ownership (TCO), Direct Product Profitability (DPP), Customer Profitability Analysis (CPA) e Efficient Consumer Response $(E C R)$ são as ferramentas indicadas para dar suporte à realização dessa gestão (LALONDE; POHLEN, 1996).

A respeito das práticas gerenciais aqui tratadas, conforme Souza et al. (2010), pode-se observar que cada uma delas tem uma aplicação particular. Os fatores principais que influenciam essa diferenciação são o foco sobre a atividade logística que se quer analisar e o tipo de informação demandada.

\subsubsection{Activity Based Costing (ABC)}

$\mathrm{O}$ método de custeio $A B C$ tem sido reconhecido e aceito por diversos autores como o modelo mais completo para análise dos custos logísticos, conforme estudos desenvolvidos por LaLonde e Pohlen (1996), Damme e Zon (1999), Cokins (2001), Souza, Collaziol e Kirch (2004) e Wang, Gao e Lin (2010). Ressalta-se que o $A B C$ também é um dos instrumentos utilizados no modelo de Wang Bo (2010), relatado na seção 2.3 deste artigo.

Para Souza, Collaziol e Kirch (2004), o $A B C$ possibilita endereçar todos os custos, incluindo custos diretos e indiretos, para produtos e clientes. A propriedade do $A B C$ decorre 
do fato de que os custos logísticos são constituídos basicamente de custos incorridos pela prestação de serviços, considerados custos indiretos.

Segundo Freires (2000), o método $A B C$ contribui para o gerenciamento dos custos logísticos na medida em que fornece informações baseadas nas atividades realizadas auxiliando a: (1) Avaliar o fluxo de processos; (2) Analisar o fluxo de processos alternativos baseado em informações econômicas; (3) Determinar o custo relativo de várias atividades e o efeito potencial de mudanças; (4) Auxiliar na identificação de produtos, clientes e canais lucrativos; e, (5) Direcionar e estabelecer o relacionamento entre empresa e fornecedores.

$\mathrm{O}$ reconhecimento das utilidades de aplicação do $A B C$ no gerenciamento do custo logístico também tem sido dado por pesquisas mais recentes (nacionais e internacionais). No âmbito nacional, tem-se o estudo de Laidens, Teles e Müller (2007) que trata da avaliação dos custos logísticos em empresas do setor alimentício. Os autores destacam que, entre os diversos métodos de custeio, o baseado em atividades mostra-se mais apropriado, dado que, nas atividades de serviços como é a logística, há forte incidência de custos indiretos, tratado com mais limitações nos métodos tradicionais, principalmente o por absorção. Há também o estudo de Vasconcellos, Marins e Muniz Junior (2008), referente à implantação do $A B C$ na logística de uma indústria química alemã.

$\mathrm{Na}$ esfera internacional, essa temática do uso apropriado do $A B C$ como instrumento de apoio à gestão logística também é predominante, conforme estudo de Everaert et al. (2008), Yanzhong (2009), Fang e Ng (2011) e Krajnc, Logozar e Korosec (2012). O entendimento comum apresentado nesses estudos é que o $A B C$ disponibiliza relatórios com informações mais transparentes sobre custos logísticos. Assim como nos estudos nacionais, há situações de aplicação do $A B C$ em uma diversidade de atividades de negócios industriais (papel, materiais de construção, petroquímicas, farmacêutica, alimentícia, eletrônica), de serviços logísticos e comércio atacadista.

O reconhecimento de que o $A B C$ é uma metodologia que possibilita superar parte das limitações presentes nos procedimentos da contabilidade de custos tradicional é frequente na literatura, aplicável inclusive como instrumento para gestão estratégica de custos e em diferentes segmentos. Os trabalhos desenvolvidos por Queiroz, Costa e Gomes (2004) e Caiado e Amaro (2006) são exemplos de estudos aplicados respectivamente para empresas desenvolvedoras de software e do setor vitivinícola.

Deve ser observado que mais recentemente, e em função de diversas manifestações a respeito das dificuldades de implantação e uso do $A B C$, Kaplan e Anderson (2004) reconfiguraram o modelo original. Eles passaram a incorporar a análise da capacidade teórica e da capacidade prática dos empreendimentos e, com base no tempo de execução das atividades, processam a alocação dos custos indiretos às atividades e destas aos objetos de custeio.

\subsubsection{Direct Product Profitability (DPP)}

$D P P$ é a técnica de gestão operacional que identifica a margem de contribuição direta do produto, levando em conta todo o processo e os custos incorridos para confecção de um item específico. Não se aplica apenas à análise dos custos logísticos, mas também ao estudo da lucratividade do produto, incluindo-se todos os custos correspondentes. A utilização do $D P P$ baseia-se no conceito do método de custeio direto, o qual disponibiliza a mensuração da margem direta do produto, conforme abordado no estudo de Souza e Diehl (2009). 
A aplicação do $D P P$, no contexto da logística, considera no cálculo da margem aqueles custos diretamente atribuídos ao produto e ao custo das atividades relacionadas, tais como: recebimento, fretes, descontos, armazenagem e trabalhos diretos. Entretanto desconsidera os custos de overhead, não diretamente relacionados ao produto, como os relacionados a atividades administrativas (LALONDE; POHLEN, 1996). Dessa forma, conforme Bookbinder e Zarour (2001), conhecer a lucratividade direta por produto permite à empresa identificar os produtos com maior margem e aqueles que precisam de uma avaliação sobre sua permanência, redução ou mesmo eliminação.

Adicionalmente, Sievanen, Suomala e Paranko (2004) indicam algumas ações que podem ser tomadas com base na análise dos resultados do DPP: (1) redefinição do preço de produtos; (2) substituição ou eliminação de produtos; (3) redesenho ou melhoria de processos; e (4) custo das atividades logísticas demandadas pelo produto. Sievanen, Suomala e Paranko (2004) acrescentam que o importante dessa análise é prover a gestão com informações para que os custos logísticos não sejam, simplesmente, uma consequência de decisões tomadas, mas, sim, um dos fatores que suportam as decisões.

\subsubsection{Customer Profitability Analysis (CPA)}

Assim como o método de custeio $A B C$ auxilia na alocação dos custos aos produtos, é possível também associar os custos logísticos aos clientes por meio dessa técnica de análise de lucratividade por cliente. $\mathrm{O} C P A$ possibilita que a administração identifique clientes não lucrativos a fim de desenvolver ações estratégicas para aumentar o retorno, ou ainda decisões sobre a manutenção ou não desses clientes (GUERREIRO; BIO; MERSCHMANN, 2008).

Para Souza, Collaziol e Kirch (2004), da receita de venda a um determinado cliente deduzem-se os descontos concedidos, impostos e custos diretos de produção. Tendo-se o resultado direto das vendas, dele são deduzidos os custos logísticos exclusivos dos serviços prestados ao cliente em análise, chegando ao lucro gerado. Tem-se assim a geração de informações úteis à análise da dimensão dos custos logísticos incorridos na operação.

Destaca-se, entretanto, que alguns resultados obtidos com essa técnica sobre clientes deficitários devem ser ponderados, pois há situações em que eles devem ser mantidos: clientes novos em processo de crescimento, aqueles que viabilizam o aprendizado sobre processos, aqueles considerados líderes do seu segmento e que podem trazer novos clientes para a empresa.

\subsubsection{Total Cost of Ownership (TCO)}

Ellram e Siferd (1998) definem o TCO como uma ferramenta que auxilia no processo de compras, além de ser considerado como uma filosofia para auxiliar na identificação dos custos totais envolvidos na aquisição de bem ou de serviço e na seleção de fornecedores.

Para Cokins (2001), o uso do custeio $A B C$ em conjunto com a técnica $T C O$ possibilita a identificação dos custos ocultos e permite sua associação a cada fornecedor. Assim, o TCO permite conhecer esses custos indiretos até então não identificados, possibilitando uma análise apurada da lucratividade por produto. Exemplificando, tais custos incluem custos de reprocessamento de pedidos e custos de setup de máquinas por atraso na entrega de materiais. Esse conceito do $T C O$ está considerado no modelo de custo total logístico desenvolvido por

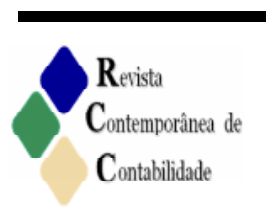

ISSN 2175-8069, UFSC, Florianópolis, v.10, n.19, p.03-32, jan./abr., 2013 
Lambert e Stock (2001), ao considerar os cinco principais fatores geradores de custos logísticos, conforme apresentado na seção 2.3 deste artigo.

Apesar de auxiliar na apuração de como o desempenho de uma empresa fornecedora da Supply Chain afeta os custos de outra empresa compradora, o TCO não possibilita a análise de custos de toda a cadeia. É um método unilateral, pois apura o quanto os custos do fornecedor interferem no resultado do comprador, mas não possibilita a análise da interferência do comprador nos fornecedores (ZANQUETTO FILHO; PIZZOLATO, 2000).

\subsubsection{Efficient Consumer Response (ECR)}

Para LaLonde e Pohlen (1996), ECR é a técnica que compreende diversos fatores para a melhoria dos custos logísticos. Em verdade, é possível compreender que o ECR é um conceito que tem como foco integrar os elos da cadeia de suprimentos com o objetivo de melhorar a resposta aos clientes finais e reduzir custos logísticos. É possível caracterizar o $E C R$ em duas fases: a primeira está relacionada à automatização das atividades ocorridas dentro da cadeia e com foco na eliminação de transações manuais; a segunda está relacionada á integração da empresa com o fornecedor, com o objetivo de tornar o reabastecimento contínuo, realizar ações conjuntas de vendas e de cross-docking (LALONDE; POHLEN, 1996).

Importante notar que o $E C R$ foca em automatizações e é suportado por tecnologias de custos logísticos. Russel (2007) define quatro categorias de sistemas de informação de apoio à implantação do ECR: (1) Enterprise Resource Planning (ERP): é o sistema corporativo de processar dados; (2) Electronic Data Interchange (EDI): facilita a conectividade entre os elos da cadeia; (3) Eletronic Product Code (EPC): facilita a administração de inventários e logística interna; (3) Radio Frequency Identification (RFID) são etiquetas capazes de identificar materiais a longa distância; e (4) Supply Chain Analytics (SCA) são sistemas de administrar a cadeia logística, com informações sobre capacidade, demanda de clientes, centros de distribuições, etc.

Especificamente quanto à gestão de custos logísticos, o $E C R$, conforme Kurnia e Johnston (2001), está focado no reabastecimento de produtos, no aumento de esforços para controle de estoques e na redução de custos logísticos de carregamento de estoques. E tudo isso é realizado ao mesmo tempo em que se procura melhorar o serviço prestado ao cliente.

A Figura 2 ilustra como essas técnicas de gestão são aplicadas na cadeia de suprimentos. Observa-se que o custeio $A B C$ permeia toda a cadeia e, dependendo do seu nível de detalhamento, pode alcançar as atividades e os custos logísticos relacionados com o consumidor final.

No sentido upstream (na direção dos fornecedores), a técnica do TCO é indicada para analisar o desempenho destes, além de todos os custos envolvidos na transação. No sentido downstream (direção aos canais de venda ou clientes), as técnicas indicadas são o DPP e $C P A$, capazes de auxiliar na medição da lucratividade por cliente e produto. Assim como o método de custeio $A B C$, a técnica operacional do $E C R$ direciona toda a cadeia para que os processos sejam otimizados, melhorando a resposta ao cliente com menores custos logísticos (FREIRES, 2000).

Freires (2000) afirma que a utilização conjunta dessas ferramentas aumenta a visibilidade dos custos ocorridos na cadeia. Ao favorecer a compreensão dos custos logísticos, ela também propicia identificar a relação entre os custos e a melhoria de processos. Mittal, 
Sarkees e Murshed (2008) reforçam a necessidade dessa análise integrada por ela considerar os elos (clientes, canais, fornecedores etc.) que influenciam os resultados das organizações.

Figura 2 - Gestão dos custos logísticos na cadeia de valor
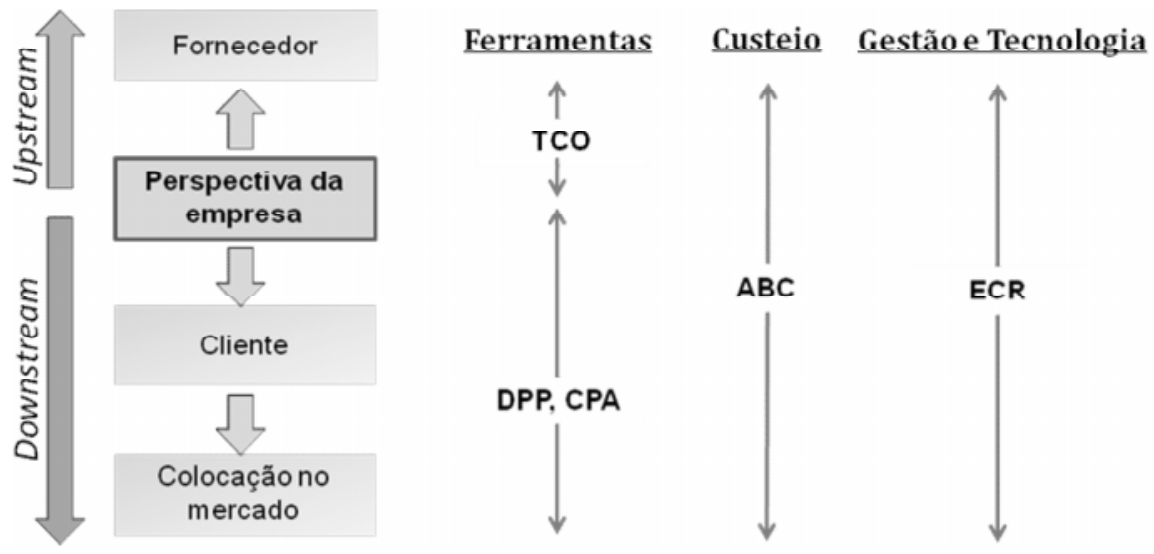

Fonte: Adaptado de Freires (2000).

Como já abordado, as práticas aqui tratadas sobre a gestão de custos logísticos são objetos da literatura há aproximadamente duas décadas (LALOND; POHLEN, 1996). Essa defasagem de tempo sinaliza a necessidade de se averiguar se elas ainda permanecem válidas e aceitas como apropriados instrumentos da gestão desejada. Além de pesquisas científicas já referidas, algumas obras didáticas consultadas referendam que essa validade e atualidade permanecem reconhecidas, conforme trabalho de Hofstetter e Jones (2006), Ballou (2006b), Avis (2009), Hutt e Speh (2009), Dinitzen e Bohlbro (2010), Koppers, Klumpp e Kürble (2010), Christopher (2010), Dent (2011).

\subsection{Estudos Relacionados}

Para Russel (2007), a partir da década de 1990, a logística tornou-se parte fundamental da gestão organizacional como fator importante para a diferenciação, passando a ser objeto de diversos estudos e análises específicas.

A presença do tema custos logísticos na agenda de pesquisas foi analisada pelos artigos publicados no Congresso USP de Controladoria e Contabilidade (2010), no Congresso Brasileiro de Custos - CBC (2010) e nos Encontros da ANPAD (2010). Analisou-se o período de 10 anos desses eventos, contemplando os anos de 2001 a 2010. Fez-se a leitura dos títulos dos trabalhos e, para aqueles relacionados ao assunto, os resumos foram analisados. Deve-se considerar que os trabalhos referentes ao CBC de 2010 só foram publicados após a conclusão deste estudo. $O$ resultado desta pesquisa consta na Tabela 1.

Os dados da Tabela 1 evidenciam a reduzida presença de artigos sobre o tema custos logísticos. De fato, no período de 10 anos foram identificados apenas 33 trabalhos sobre o tema, correspondentes a apenas $0,9 \%$ do total de artigos aprovados, apesar da relevância do tema na literatura, conforme estudos de Ilos (2008) e Russel (2007). 
Tabela 1 - Análise dos trabalhos aprovados em congressos nacionais

\begin{tabular}{|c|c|c|c|c|c|c|c|c|c|}
\hline \multirow{3}{*}{ Ano } & \multicolumn{3}{|c|}{ EnANPAD } & \multicolumn{3}{|c|}{ Congressos USP } & \multicolumn{3}{|c|}{ Congressos Brasileiro Custos } \\
\hline & \multirow{2}{*}{ Total } & \multicolumn{2}{|c|}{ Custos Logísticos } & \multirow{2}{*}{ Total } & \multicolumn{2}{|c|}{ Custos Logísticos } & \multirow{2}{*}{ Total } & \multicolumn{2}{|c|}{ Custos Logísticos } \\
\hline & & Qtd & $\%$ & & Qtd & $\%$ & & Qtd & $\%$ \\
\hline 2010 & 48 & 1 & 2,1 & 101 & 0 & 0 & - & - & - \\
\hline 2009 & 58 & 0 & 0 & 68 & 0 & 0 & 253 & 2 & 0,8 \\
\hline 2008 & 77 & 1 & 1,3 & 84 & 0 & 0 & 267 & 4 & 1,5 \\
\hline 2007 & 81 & 1 & 1,2 & 120 & 0 & 0 & 238 & 4 & 1,7 \\
\hline 2006 & 63 & 0 & 0 & 150 & 0 & 0 & 212 & 2 & 0,9 \\
\hline 2005 & 69 & 0 & 0 & 100 & 2 & 2,0 & 350 & 3 & 0,9 \\
\hline 2004 & 106 & 0 & 0 & 100 & 0 & 0 & 244 & 6 & 2,5 \\
\hline 2003 & 82 & 0 & 0 & 100 & 1 & 1,0 & 140 & 2 & 1,4 \\
\hline 2002 & 69 & 0 & 0 & 85 & 0 & 0 & 200 & 2 & 1,0 \\
\hline 2001 & 36 & 0 & 0 & 74 & 1 & 1,4 & 134 & 1 & 0,7 \\
\hline Total de 10 anos & 689 & 3 & 0,4 & 982 & 4 & 0,4 & 2038 & 26 & 1,3 \\
\hline
\end{tabular}

\begin{tabular}{|l|r|}
\hline Total de artigos pesquisados & 3.709 \\
\hline Total sobre Custos Logísticos & 33 \\
\hline$\%$ de artigos sobre custos logíticos & $0,89 \%$ \\
\hline
\end{tabular}

Fonte: ANPAD (2010), USP (2010) e ABC (2010).

Observa-se que a maioria dos trabalhos está presente no Congresso Brasileiro de Custos. A leitura desses 33 trabalhos identifica que 14 deles (42\%) são trabalhos teóricos, elaborados sob a forma de revisão bibliográfica. Dos trabalhos restantes, nove (27\%) foram destinados a mensurar os custos logísticos em empresas, cinco $(15 \%)$ objetivaram analisar a relevância dos custos logísticos em relação ao custo total. Do total de 33 trabalhos, apenas quatro (12\%) assemelham-se aos objetivos deste estudo, ou seja, investigam as práticas de gestão dos custos logísticos adotadas pelas empresas, analisadas de forma comparativa ao tratamento dado pela literatura.

Uma revisão mais abrangente da literatura, para além de trabalhos apresentados em congressos, possibilita compreender melhor como a mensuração e a análise de custos logísticos têm sido tratadas em pesquisas empíricas recentes publicadas em periódicos científicos (Quadro 4).

Quadro 4 - Estudos empíricos relacionados a custos logísticos

\begin{tabular}{|c|l|l|}
\hline Autor / Ano & \multicolumn{1}{|c|}{ Título } & \multicolumn{1}{|c|}{ Principais Resultados } \\
\hline $\begin{array}{c}\text { Sievanen, } \\
\begin{array}{c}\text { Suomala e } \\
\text { Paranko } \\
(2004)\end{array}\end{array}$ & $\begin{array}{l}\text { Product profitability: causes and } \\
\text { effects }\end{array}$ & $\begin{array}{l}\text { Estudo de caso em uma indústria metalúrgica com } \\
\text { implantação do ABC para custeio e mensuração da } \\
\text { lucratividade por produto (DPP). Constata alta variação } \\
\text { na lucratividade apurada anteriormente com uso do } \\
\text { custeio variável. Viabiliza outras informações antes } \\
\text { não detalhadas. }\end{array}$ \\
\hline $\begin{array}{c}\text { Robles Jr, } \\
\text { Robles e Faria } \\
(2005)\end{array}$ & $\begin{array}{l}\text { Custos para servir: uma proposta } \\
\text { de aplicação para uma empresa de } \\
\text { tintas }\end{array}$ & $\begin{array}{l}\text { Estudo de caso único em uma indústria de tintas. } \\
\text { Identificou que há carência de informações de custos e } \\
\text { não aplicação de técnicas como CPA, DPP, TCO e } \\
A B C .\end{array}$ \\
\hline
\end{tabular}




\begin{tabular}{|c|c|c|}
\hline $\begin{array}{l}\text { Laidens, Teles } \\
\text { e Müller } \\
\quad \text { (2007) }\end{array}$ & $\begin{array}{l}\text { Avaliação dos custos logísticos em } \\
\text { empresas do setor alimentício }\end{array}$ & $\begin{array}{l}\text { Estudo de caso com duas empresas do setor } \\
\text { alimentício. Identificou utilização de } \\
\text { tradicionais de custos (custeio por absorção e custo- } \\
\text { padrão). Não utilizam o } A B C, D P P, C P A \text { e } T C O \text {. }\end{array}$ \\
\hline $\begin{array}{l}\text { Guerreiro, Bio } \\
\text { e Merschmann } \\
\quad(2008)\end{array}$ & $\begin{array}{l}\text { Cost-to-serve measurement and } \\
\text { costumer profitability analysis }\end{array}$ & $\begin{array}{l}\text { Estudo de caso em uma indústria alimentícia brasileira. } \\
\text { Uso do } A B C \text { para mensuração do custo para servir e } \\
\text { consequente gestão da lucratividade por cliente }(C P A) \text {. } \\
\text { Conclui que o } A B C \text { disponibiliza informações } \\
\text { específicas não detalhadas nas análises tradicionais }\end{array}$ \\
\hline $\begin{array}{l}\text { Everaert et al. } \\
\qquad(2008)\end{array}$ & $\begin{array}{l}\text { Cost modeling in logistics using } \\
\text { time-driven } A B C: \text { experiences from } \\
\text { a wholesaler }\end{array}$ & $\begin{array}{l}\text { Estudo de caso em uma empresa atacadista. A } \\
\text { aplicação do TDABC mostrou-se mais apropriado que } \\
\text { o } A B C \text { original no fornecimento de informações sobre } \\
\text { custos logísticos }\end{array}$ \\
\hline $\begin{array}{l}\text { Hua } \\
(2008)\end{array}$ & $\begin{array}{l}\text { Status and controlling measures of } \\
\text { logistics cost in China's logistics } \\
\text { industry }\end{array}$ & $\begin{array}{l}\text { Análise de práticas de controle de custos logísticos de } \\
\text { empresas chinesas. Identifica predominância da } \\
\text { contabilidade de custos tradicional e não uso de } \\
\text { práticas mais apropriadas. }\end{array}$ \\
\hline $\begin{array}{l}\text { Vasconcellos, } \\
\text { Marins e } \\
\text { Muniz Júnior } \\
\text { (2008) }\end{array}$ & $\begin{array}{l}\text { Implantação do método activity } \\
\text { based costing na logística interna } \\
\text { de uma empresa química }\end{array}$ & $\begin{array}{l}\text { Estudo de caso em uma indústria química alemã } \\
\text { instalada no Brasil. A implantação do custeio } A B C \\
\text { possibilitou melhor identificar e mensurar os custos } \\
\text { logísticos e direcionar ações de melhoria de processo. }\end{array}$ \\
\hline $\begin{array}{r}\text { Yanz } \\
(20\end{array}$ & $\begin{array}{l}\text { Logistics cost management in } \\
\text { emerging market: evidence from } \\
\text { China }\end{array}$ & $\begin{array}{l}\text { Pesquisa com } 126 \text { empresas de diversos segmentos de } \\
\text { negócio identifica que somente } 2,9 \% \text { utilizam o } D P P \text {, } \\
2,4 \% \text { o } T C O, 34,9 \% \text { o } A B C, 29,4 \% \text { o custo-meta e } 54 \% \\
\text { a contabilidade de custos tradicional. }\end{array}$ \\
\hline $\begin{array}{r}\text { Somı } \\
(20\end{array}$ & $\begin{array}{lr}\text { Modeling outbound logistics } & \text { cost } \\
\text { management } \quad \text { system } & \text { of } \\
\text { manufacturing companies } & \text { in } \\
\text { Southwestern, Nigéria } & \\
\end{array}$ & $\begin{array}{l}\text { Pesquisa com } 20 \text { empresas nigerianas. Desenvolve } \\
\text { modelo que identifica relações entre custos de } \\
\text { distribuição e custos logísticos totais. Utiliza o conceito } \\
\text { de } T C O \text {. }\end{array}$ \\
\hline $\begin{array}{l}\text { Wang, Gao e } \\
\text { Lin } \\
(2010)\end{array}$ & $\begin{array}{l}\text { Using } A B C \text { to improve the logistics } \\
\text { value chain in a chinese food } \\
\text { product company }\end{array}$ & $\begin{array}{l}\text { Estudo de caso em uma empresa chinesa de produtos } \\
\text { de consumo. Com o } A B C / A B M \text { há informações mais } \\
\text { corretas do que pelo absorção: identifica atividades que } \\
\text { não agregam valor e ações de melhorias. Mensura } \\
\text { melhor o } D P P \text { e o } C P A \text {. }\end{array}$ \\
\hline $\begin{array}{l}\text { Vodenicharova } \\
\qquad(2011)\end{array}$ & $\begin{array}{l}\text { Cluster analysis of Bulgarian meat } \\
\text { processing industry }\end{array}$ & $\begin{array}{l}\text { Análise da gestão logística de } 58(15 \%) \text { empresas } \\
\text { búlgaras processadoras de produtos alimentícios. } \\
\text { Identifica baixo uso de tecnologias de sistemas de } \\
\text { informações; prevalece a experiência prática e baixa } \\
\text { integração interna das atividades logísticas. }\end{array}$ \\
\hline $\begin{array}{l}\text { Krajnc, } \\
\text { Logozar e } \\
\text { Korosec } \\
(2012)\end{array}$ & $\begin{array}{l}\text { Activity-based management of } \\
\text { logistic costs in a manufacturing } \\
\text { company }\end{array}$ & $\begin{array}{l}\text { Estudo de caso em uma empresa Eslovena produtora de } \\
\text { papel. Com a criação de um modelo de custeio baseado } \\
\text { no } A B C \text { há } 108 \% \text { de visibilidade a mais dos custos } \\
\text { logísticos em relação ao custeio por absorção. }\end{array}$ \\
\hline
\end{tabular}

Fonte: Elaborado pelos autores.

Observa-se que é predominante, nesses 12 estudos empíricos apresentados, o enfoque dado ao custeio $A B C$. Para os pesquisadores analisados parece que os métodos de custeio por absorção, variável e outros tradicionais não atendem de forma adequada às necessidades de informações de custos logísticas para gestão, presente em 50\% dos estudos listados no Quadro 4. Quanto às demais práticas tratadas neste estudo (DPP, CPA, TCO), elas aparecem em situações de exceção e sem muito destaque.

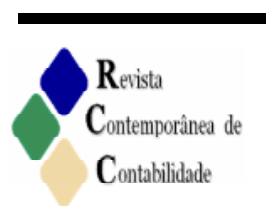


Diante dos dados apresentados no Quadro 4, e tomando essas pesquisas como base de avaliação e generalização, as práticas mais discutidas na literatura de custos, com exceção do $A B C$, não parecem encontrar muito espaço de aplicação em empresas de diversos países e segmentos. Apesar de os artigos não tratarem dessa questão, é necessário que se explorem mais as causas da não adoção das citadas práticas pelas empresas. Essa pode ser uma grande contribuição para se avaliar a penetração dos desenvolvimentos teóricos na vida real das empresas. Não se deve descartar aqui a possibilidade de que as pesquisas talvez não tenham tido objetividade suficiente em seus processos investigatórios para colher mais informações sobre essa realidade.

Além desses artigos apresentados no Quadro 4, outros foram identificados por tratarem do tema, porém sob um escopo teórico a respeito das práticas de gestão de custos logísticos (Quadro 5).

Quadro 5 - Estudos teóricos relacionados a custos logísticos

\begin{tabular}{|c|c|c|}
\hline Autor / Ano & Título & Foco do Estudo \\
\hline $\begin{array}{l}\text { Ballou } \\
\text { (2006b) }\end{array}$ & $\begin{array}{l}\text { The evolution and future of } \\
\text { logistics and supply chain } \\
\text { management }\end{array}$ & $\begin{array}{l}\text { Discute a necessidade de uso do conceito } T C O \text { para } \\
\text { gerenciamento coletivo de atividades logísticas; uso do } \\
A B C \text { para mensuração e gerenciamento de custos } \\
\text { logísticos. }\end{array}$ \\
\hline $\begin{array}{l}\text { Hua } \\
(2008)\end{array}$ & $\begin{array}{l}\text { Status and controlling measures } \\
\text { of logistics cost in China's } \\
\text { logistics industry }\end{array}$ & $\begin{array}{l}\text { Trata da importância da gestão dos custos logísticos } \\
\text { como questão estratégica; critica a contabilidade de custo } \\
\text { tradicional por não revelar os custos logísticos e enfatiza } \\
\text { a utilidade do } A B C \text {. }\end{array}$ \\
\hline $\begin{array}{l}\text { Zhao e Tanq } \\
\qquad(2009)\end{array}$ & $\begin{array}{l}\text { Analysis and strategy chinese } \\
\text { logistics cost reduction }\end{array}$ & $\begin{array}{l}\text { Discute a perda de informações sobre os custos } \\
\text { logísticos, pois, a contabilidade de custo tradicional } \\
\text { apenas os trata como parte dos custos indiretos; sugere a } \\
\text { criação de uma contabilidade gerencial logística. }\end{array}$ \\
\hline $\begin{array}{l}\text { Koopers, } \\
\text { Klump e } \\
\text { Kürle } \\
(2010)\end{array}$ & $\begin{array}{l}\text { Value chain management: } \\
\text { integrating marketing and } \\
\text { logistics }\end{array}$ & $\begin{array}{l}\text { Demonstra uma comparação entre } E C R, S C M \text { e sistema } \\
\text { vertical de marketing para identificar diferenciadores de } \\
\text { competição. }\end{array}$ \\
\hline $\begin{array}{c}\text { Souza e Pires } \\
(2010)\end{array}$ & $\begin{array}{l}\text { Theory of } \\
\begin{array}{l}\text { contributions } \\
\text { logistics }\end{array} \text { to outbound }\end{array}$ & $\begin{array}{l}\text { Descreve sistematicamente as principais contribuições } \\
\text { práticas da teoria das restrições (TOC) nos custos de } \\
\text { distribuição, superior ao sistema principalmente baseado } \\
\text { nas vendas. }\end{array}$ \\
\hline $\begin{array}{c}\text { Fang e Ng } \\
\text { (2011) }\end{array}$ & $\begin{array}{l}\text { Applying activity-based costing } \\
\text { approach for construction } \\
\text { logistics cost analysis }\end{array}$ & $\begin{array}{l}\text { Examina um sistema de controle e análise de custos. } \\
\text { Mediante o uso do } A B C \text { os custos podem ser rastreados } \\
\text { das atividades ao consumo de um particular elemento de } \\
\text { custo logístico. }\end{array}$ \\
\hline $\begin{array}{l}\text { Bokor } \\
(2012)\end{array}$ & $\begin{array}{l}\text { logistics } \quad \text { cost } \\
\text { into } \quad \text { production }\end{array}$ & $\begin{array}{l}\text { Desenvolve um sistema multi critério, baseado nos } \\
\text { conceitos do } A B C \text {, análise de processos }(A H P) \text { e análise } \\
\text { envoltória de dados }(D E A) \text {. A finalidade é reduzir as } \\
\text { arbitrariedades e distorções das alocações dos custos } \\
\text { logísticos quando do custeio dos produtos. }\end{array}$ \\
\hline
\end{tabular}

Fonte: Elaborado pelos autores.

Nesses estudos teóricos propositivos, observa-se a ausência das práticas objeto deste estudo ( $D P P, C P A, D P O L, T C O, A B C)$. A exceção é a apresentação do $A B C$ como instrumento de avaliação dos custos logísticos, dadas as limitações da contabilidade de custos tradicional que os tratam como custo dos produtos, sem qualquer discriminação. Apesar de esses estudos teóricos não inovarem em suas propostas, devem ser reconhecidos os esforços 
para estruturar um sistema que possibilite tratar de forma diferenciada as informações relacionadas aos processos e serviços logísticos.

Exceções de inovação são identificadas, tais como: os esforços de Bokor (2012), os quais se diferenciam por utilizar outras técnicas de análises como a $A H P$ e DEA para desenvolver um modelo que isole os custos logísticos, mas que os integre aos custos dos produtos; e os estudos de Koopers, Klump e Kürle (2010), os quais procuram desenvolver métodos que envolvam a utilização conjunta do $E R C$ e da $S C M$ como forma de identificar fatores diferenciadores de competitividade pela análise dos custos logísticos. Ballou (2006b) é o que mais se aproxima das técnicas de gestão de custos logísticos tratadas neste estudo, haja vista a utilização da $T C O$ e $A B C$ na mensuração dos custos logísticos.

Souza e Pires (2010) também apresentam similaridade com esses estudos, porém apenas parcial, já que está focado no uso da $T C O$ e $A B C$ no tratamento dos custos de distribuições, assumindo que a contabilidade gerencial não consegue atender a esses objetivos. Hua (2008) trata das medidas de custos e controle de custos logísticos em empresas chinesas, para o que recomenda a utilização do $A B C$. Zhao e Tang (2009) discorrem sobre os diversos fatores que provocam custos logísticos elevados na China. Para eles isso passa por deficiências de políticas governamentais e por deficiências de uma logística integrada pelas empresas dada a inexistência de sistemas de informações que tratem adequadamente os custos logísticos, deixando de considerá-los como parte dos custos indiretos. Por fim, sugerem a criação de uma contabilidade logística gerencial.

\section{Procedimentos Metodológicos}

\subsection{Classificação Metodológica}

O estudo caracteriza-se por ter uma abordagem qualitativa quanto ao problema de pesquisa. Segundo Saha e Corley (2006), os principais benefícios do método incluem a possibilidade de os pesquisadores descobrirem novas variáveis e relações além de revelar e entender processos mais complexos em seu ambiente de ocorrência.

Quanto aos objetivos é uma pesquisa de caráter descritivo e exploratório. Gil (1999) comenta que a pesquisa descritiva visa descrever as características de determinada população ou fenômeno, ou o estabelecimento de relações entre variáveis. Ainda segundo Gil (1999), a pesquisa exploratória proporciona mais familiaridade com o objeto de estudo, tentando tornálo explícito ou a construir hipóteses.

A pesquisa foi desenvolvida por meio de estudo de caso único aplicado em uma empresa brasileira, localizada no estado do Rio Grande do Sul, de atuação no segmento alimentício, considerada de médio-grande porte de acordo com a classificação definida pelo BNDES (2010). Para Eisenhardt (1989), os estudos de casos devem ser focados no entendimento da dinâmica que está presente em um cenário ou ambiente.

Como forma de manter o rigor da pesquisa cientifica, foi realizado um protocolo de estudo de caso, conforme indicado por Yin (2001), apresentado ao final desta seção do trabalho.

\subsection{Procedimentos de Coleta e Análise de Dados}


A coleta de dados ocorreu por meio de entrevistas semiestruturadas, realizadas com os responsáveis pelas áreas de custos, suprimentos e logística, além de um consultor contábil da empresa. Conforme Lakatos e Marconi (1999), nesse tipo de entrevista segue-se um roteiro previamente estabelecido e, caso necessário, incluem-se novas questões para atingir o objetivo.

Foi realizado um procedimento de pré-teste do roteiro da entrevista com a participação de dois executivos da área de contabilidade de empresas de grande porte. As principais melhorias foram: (1) inclusão de questões mais profundas sobre práticas de gestão e análise de custos logísticos; (2) inclusão de questões sobre projetos para uso de novas técnicas de análise; e, (3) inclusão de questões sobre o processo logístico.

O Quadro 6 apresenta uma breve caracterização dos entrevistados.

Quadro 6 - Perfil dos entrevistados

\begin{tabular}{|l|l|l|l|}
\hline \multicolumn{1}{|c|}{ Cargo } & \multicolumn{1}{|c|}{ Área de atuação } & \multicolumn{1}{c|}{$\begin{array}{c}\text { Tempo de } \\
\text { empresa }\end{array}$} & \multicolumn{1}{c|}{ Formação acadêmica } \\
\hline Gerente de Compras & Compras & 19 anos & Graduado em Administração \\
\hline Gerente Comercial & Comercial e Logística & 13 anos & Graduado em Administração \\
\hline Controller & Controladoria e Custos & 11 anos & Pós-Graduado em Ciências Contábeis \\
\hline Consultor & Contabilidade e Custos & $\begin{array}{l}5 \text { anos de } \\
\text { consultoria }\end{array}$ & Mestre em Ciências Contábeis \\
\hline
\end{tabular}

Fonte: Dados da pesquisa.

Observa-se pela caracterização dos entrevistados a abrangência e a relação da atuação deles com o tema da pesquisa, com destaque para as áreas de suprimentos (entradas de materiais), comercial e logística (movimentação interna e distribuição) e financeira (contabilidade e custos). Além das entrevistas, realizadas no período de outubro a dezembro de 2010, utilizou-se também a técnica de análise documental, feita em relatórios contábeis e gerenciais da empresa, visando melhor compreender as informações apresentadas no estudo.

A análise dos dados foi realizada por meio interpretativo, em que são realizadas reflexões sobre os dados e as informações coletadas e pela compreensão dos fatos, levando em consideração a relevância e a contribuição específica deles para o estudo do tema abordado.

Além disso, os resultados obtidos na análise dos dados foram comparados com os resultados da pesquisa realizada nos anais de congressos nacionais e em periódicos, nacionais e internacionais, possibilitando assim uma visão mais abrangente sobre o significado dos resultados da pesquisa.

\subsection{Apresentação do Protocolo do Estudo de Caso}

Para Gil (2010, p. 120), "não existe uma modelo fixo para elaboração do protocolo, mas recomenda-se que seja subdividido em partes [...]". Segundo Yin (2001), o protocolo utilizado se divide em três partes que orientam o pesquisador em diferentes momentos da pesquisa, sendo eles: visão geral do estudo de caso e ambiente geral da empresa, entrevistas com os profissionais de cargos selecionados e, por fim, a análise documental.

Portanto, no protocolo do estudo de caso desenvolvido, seguiu-se a estrutura apresentada no Quadro 7, de acordo com as proposta de Yin (2010) e Gil (2010): 


\begin{tabular}{|c|c|}
\hline & Quadro 7 - Protocolo de estudo \\
\hline 1 & Dados de identificação: Título do projeto, nome dos responsáveis, período e local de realização. \\
\hline 2 & $\begin{array}{l}\text { Introdução ao estudo de caso e finalidade do protocolo: Papel do protocolo na orientação do } \\
\text { investigador do estudo de caso. }\end{array}$ \\
\hline 3 & $\begin{array}{l}\text { Procedimento de coleta de dados: Definição das instituições e pessoas que constituirão o objeto de } \\
\text { pesquisa; definição de agenda para a coleta de dados, nomes dos locais a serem visitados, bem como do } \\
\text { perfil dos respondentes e do ambiente de operações da empresa relacionada. }\end{array}$ \\
\hline 4 & $\begin{array}{l}\text { Questões do estudo de caso: Questões a serem utilizadas na coleta de dados, baseados no problema ou } \\
\text { nas questões mais amplas de pesquisa, precedidas de procedimentos de pré-teste. }\end{array}$ \\
\hline 5 & $\begin{array}{l}\text { Guia para elaboração do relatório: Está relacionado com a classificação dos eventos, referências a } \\
\text { documentos importantes e lista de pessoas entrevistadas. }\end{array}$ \\
\hline 6 & $\begin{array}{l}\text { Banco de dados: Os documentos a serem coletados, questionários aplicados aos gestores da empresa e } \\
\text { outros documentos impressos utilizados durante a pesquisa e que serão mantidos em arquivos pelo } \\
\text { pesquisador. Possíveis verificações in loco no campo das operações. }\end{array}$ \\
\hline 7 & $\begin{array}{l}\text { Relatório da Pesquisa: envolve a utilização e análise dos dados e informações coletadas junto aos } \\
\text { participantes da pesquisa, via questionário ou observação documental. Redação do relatório da pesquisa à } \\
\text { luz dos seus objetivos e com base no material coletado com os participantes. }\end{array}$ \\
\hline
\end{tabular}

Fonte: Elaborado com base em Yin (2010, p. 107) e Gil (2010, p. 120).

\section{Apresentação e Análise de Dados}

\subsection{Descrição Geral da Empresa Pesquisada}

De origem brasileira e com capital fechado, a empresa possui uma unidade instalada no Rio Grande do Sul e outras duas em fase de construção na região Centro-Oeste do País. Atua há mais de 20 anos na industrialização e comercialização de produtos alimentícios, tendo presente no seu quadro de pessoal cerca de 300 funcionários. Suas operações comerciais estão voltadas para $86 \%$ para o mercado interno. O faturamento bruto anual está em aproximadamente $\mathrm{R} \$ 156$ milhões, registrados no ano de 2011, distribuído por vários estados do País. Apesar dessa representatividade econômica, trata-se de uma empresa familiar cujo comando decisório acha-se concentrado em gestores da família proprietária. Esse perfil da gestão não tem impedido o contínuo crescimento da empresa. O processo de reestruturação do sistema de informação e integração de diversas atividades, inclusive de avanços na gestão de custos e da logística, são ações que merecem destaque.

Conforme relatório da gerência comercial, a grande concentração do faturamento está nas regiões Sul e Centro-Oeste do País, representando cerca de 70\% do total. Destaca-se que a empresa adota como predominante o enfoque competitivo da diferenciação, atuando em um mercado com baixa concorrência tanto interna quanto externamente.

Informações dadas pelo controller revelam que historicamente a empresa utilizava procedimentos básicos para análise e controle de custos com planilhas eletrônicas. Com o crescimento das atividades, a empresa buscou sistemas específicos para a gestão das operações. A área de custos foi implantada em 2009 com o apoio de consultorias e de um novo sistema de informações. Desde então, ampliaram-se as atividades de geração de informações e relatórios gerenciais de custos, inclusive quanto aos custos logísticos. Foi informado ainda que faz parte desse sistema incorporar novos instrumentos gerenciais que permitam ampliar a capacidade da gestão logística da empresa.

A empresa utiliza o método da contabilidade de ganhos como ferramenta gerencial de apoio às decisões. Com o cálculo da margem de ganho, é identificado o resultado econômico

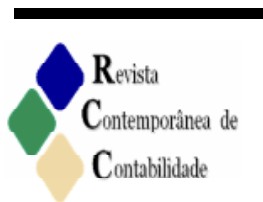


por cliente, representante, mercado, unidade de negócio e produto. O controller e o consultor explicaram que, para o cálculo da margem de ganho, se excluem das receitas operacionais as deduções peculiares (tributos, comissões, fretes e custos diretos) de cada um dos mercados de comercialização dos produtos, conhecendo-se assim o potencial de ganho de cada um deles. $\mathrm{O}$ acesso a relatórios gerenciais disponibilizados pelo controller possibilitou verificar que esse procedimento é adotado para clientes e produtos considerados representativos em termos de faturamento. Conforme esclarecido, o consultor tem parte de suas atividades ligadas ao sistema de informações que disponibiliza tais relatórios.

Observa-se aqui uma primeira divergência entre os procedimentos de custeio adotados pela empresa (a contabilidade e margem de ganho), haja vista a ampla preferência da literatura a respeito das contribuições do uso do $A B C$ ou mesmo da absorção tradicional. Em apenas um dos estudos pesquisados, teve-se referência ao uso do custeio variável (KRAJNC; LOGOZAR; KOROSEC, 2012) e com acentuadas críticas às limitações do seu uso.

\subsection{Estrutura da Logística de Suprimentos e de Distribuição}

Apesar da importância dada às atividades de logística, a empresa não possui um departamento específico para esse fim, mas conta com setores distintos que realizam partes do processo de logística (Figura 3). Conforme esclarecido pelo gerente comercial e logística, o plano de expansão da empresa já estabelece em seu futuro organograma a criação de uma área especificamente direcionada a concentrar as atividades ligadas às atividades logísticas, inclusive a dos custos relacionados.

Há um setor de compras, que negocia com fornecedores a aquisição dos materiais demandados pelas operações; um setor comercial, que mantém contato com os clientes, junto com representantes que estão distribuídos em todo o território nacional; há também uma assessoria específica para as compras e as vendas realizadas no mercado externo. O conteúdo da Figura 3 foi extraído de material fornecido pelo controller.

Figura 3 - Organograma das áreas da empresa

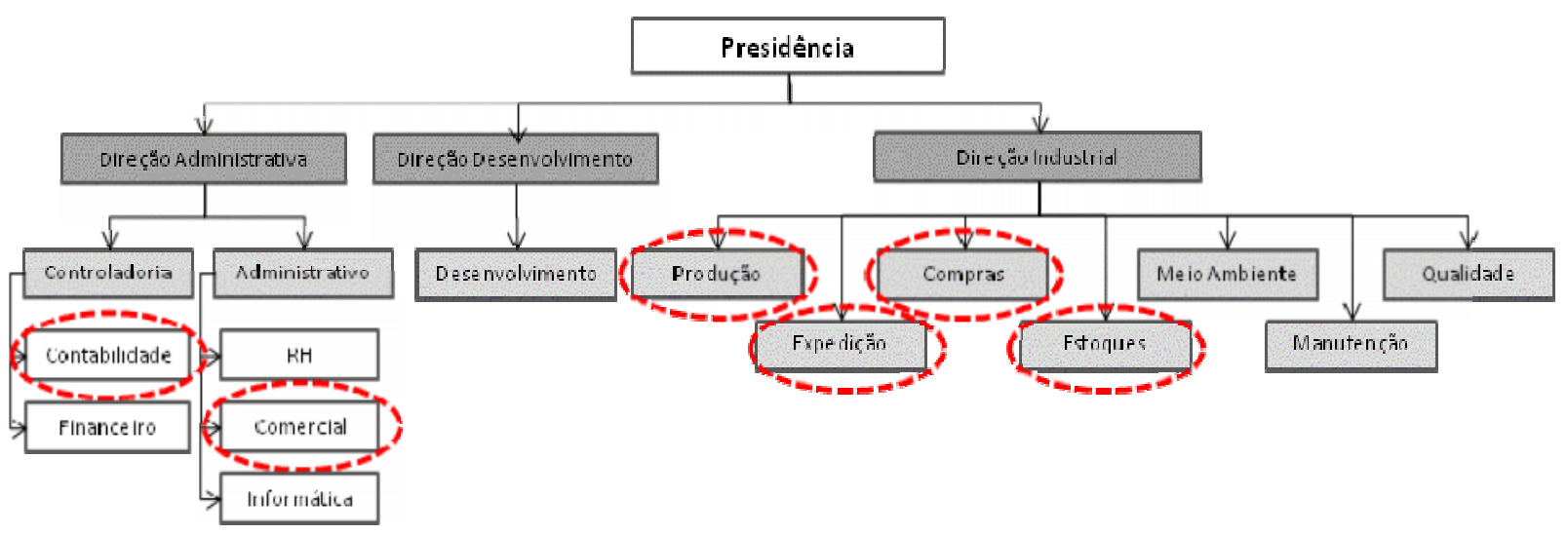

Fonte: Dados da pesquisa.

Essa integração parece ser uma sinalização evidente do crescimento e da importância que a área de logística vem conquistando na gestão operacional da empresa. De fato, conforme destacam Krajnc, Logozär e Krosec (2012), a existência de um sistema de logística integrado é fator determinante para o sucesso na gestão de material e de serviços logísticos. 
Esse entendimento também foi dado por Vodenicharova (2011), a qual destaca que a não integração logística é uma das principais deficiências das empresas búlgaras processadoras de alimento.

\subsection{Principais Aspectos Operacionais da Logística e seus Impactos em Custos}

A logística realizada pela empresa para integração com a cadeia de suprimentos é considerada um fator estratégico. No que tange ao departamento de compras, a empresa tem como política comprar de maneira que consiga obter melhores condições de preços. Além disso, também são levados em consideração os prazos de entrega, uma vez que a matériaprima principal, representante de $80 \%$ dos custos totais, é transportada de outros estados e requer cuidados especiais. Conforme apresentado pelo gerente de compras, mensalmente são elaborados relatórios gerenciais que evidenciam os dados negociais das principais transações. Tais relatórios também são o produto dos serviços de consultoria externa.

$\mathrm{O}$ gerente comercial informou que, quanto à política de comercialização com novos clientes, a empresa busca trabalhar com um valor mínimo de faturamento para entregas no sistema Cost Insurance Freight $(C I F)$. Abaixo desse valor mínimo, a entrega é feita sob as condições Free On Board (FOB). Esse fato faz com que os clientes programem pedidos com valor suficiente para que o frete seja livre. Conforme esclarecido pelo gerente comercial, o valor mínimo é estabelecido em conjunto com a avaliação da controladoria.

Informações do gerente comercial destacam que as vendas realizadas para o estado do Rio Grande do Sul, que representam 19\% do total, são entregues utilizando veículos da frota própria. Para os estados de Santa Catarina, Paraná e São Paulo, correspondentes a $41 \%$ das vendas totais, as entregas são feitas de forma fracionadas ou fechadas. Para os clientes localizados nos outros estados, a entrega é feita por uma transportadora até São Paulo, onde é realizado o redespacho para entrega no destino final. Ainda de acordo com o gerente comercial, devido à distância, ao tempo e ao custo para a realização das entregas, a empresa tem como estratégia produzir conforme os pedidos, mantendo um estoque mínimo suficiente para solicitações recebidas com menos de 48 horas.

Como já destacado pela literatura, o custo logístico com frete é talvez o mais expressivo, fazendo com que as empresas estabeleçam formas operacionais visando reduzir o seu impacto, como é o caso apresentado no presente estudo ( $72 \%$ do custo logístico total). Zhao e Tang (2009) destacam que, além da esfera macro, relativa à atuação governamental (política nacional de meios de transportes), há também a esfera micro que corresponde à parte do problema que pode ser gerenciado por políticas próprias, como apresentado pelo gerente comercial da empresa pesquisada.

\subsection{Gerenciamento dos Custos Logísticos}

Conforme informado pelo controller, como a área de custos é recente, ainda existem diversos controles que estão sendo aperfeiçoados ou implantados para melhor atender às demandas por informações gerenciais. Assim, os custos logísticos são controlados por relatórios gerenciais e por meio de indicadores financeiros e não financeiros apresentados em reuniões mensais. Os principais indicadores utilizados são: reclamações de clientes por atrasos na entrega, número de avarias no transporte, índice de devoluções de produtos, tempo do ciclo do pedido até a entrega e variações nos custos logísticos controlados. O consultor 
acrescentou que um pacote sistematizado e integrado de relatórios gerenciais está em fase final de desenvolvimento e testes, contemplando mais robustez na abrangência e no conteúdo dos indicadores. Verifica-se, pelas indicações apresentadas, que a empresa tem, ainda, limitações pela não integração de sistema de informações e controles não financeiros que possam sinalizar possíveis não conformidades nos procedimentos operacionais.

Conforme informado pelo controller, os custos logísticos são relevantes para a empresa e representam 4,5\% do faturamento total, equivalente a aproximadamente $\mathrm{R} \$ 7$ milhões, e 8,3\% do custo total dos produtos vendidos. Ele acrescentou que dadas as limitações do sistema ainda em uso, esses valores são estimativas aceitáveis de valores apontados de forma extracontábil em planilhas eletrônicas. O Quadro 8, elaborado com base nas planilhas eletrônicas disponibilizadas pelo controller, apresenta em detalhes como estão distribuídos os custos logísticos e sua representatividade para a empresa.

Quadro 8 - Custos logísticos monitorados pela empresa

\begin{tabular}{|c|c|c|}
\hline Custos Logísticos & $\%$ & Controle realizado pela empresa \\
\hline Níveis de serviço & - & $\begin{array}{l}\text { A empresa não realiza o controle sobre esses custos, mas já analisa a } \\
\text { possibilidade de iniciar este controle visto existirem projetos para melhoria } \\
\text { dos níveis de serviço. }\end{array}$ \\
\hline Custos de lotes & - & $\begin{array}{l}\text { A empresa não realiza o controle sobre esses custos, mas reconhece a } \\
\text { importância da sua análise, por isso, pretende implantar o seu controle no } \\
\text { futuro. }\end{array}$ \\
\hline $\begin{array}{l}\text { Custos de } \\
\text { embalagens }\end{array}$ & 15 & $\begin{array}{l}\text { São mensurados com mais detalhes, uma vez que são aplicados aos produtos } \\
\text { conforme exigências de cada cliente. }\end{array}$ \\
\hline $\begin{array}{c}\text { Custos de } \\
\text { armazenagem }\end{array}$ & 4 & $\begin{array}{l}\text { A armazenagem interna não é custeada. A armazenagem externa, usada para } \\
\text { a matéria-prima principal, é custeada, a saber: aluguel do depósito, seguro e } \\
\text { quebra técnica oriunda de cargas e descargas. }\end{array}$ \\
\hline $\begin{array}{l}\text { Custos de } \\
\text { manutenção de } \\
\text { inventário }\end{array}$ & 9 & $\begin{array}{l}\text { São controladas questões referentes a materiais obsoletos, avarias de } \\
\text { produtos do estoque, custos com seguros e de oportunidade. Como a } \\
\text { disponibilidade de compra da matéria-prima é influenciada diretamente pelo } \\
\text { clima, a companhia aceita um custo adicional de inventário para garantir a } \\
\text { entrega aos clientes. Essas margens são monitoradas a fim de reduzir ao } \\
\text { máximo o investimento em estoques adicionais. }\end{array}$ \\
\hline $\begin{array}{l}\text { Custos de } \\
\text { processamento de } \\
\text { pedidos e de TI }\end{array}$ & - & $\begin{array}{l}\text { A empresa não realiza o controle sobre esses custos por não considerar } \\
\text { relevantes sobre o montante do custo total. A expectativa (conforme o } \\
\text { controller) é que isso mude após a fase de expansão da empresa. }\end{array}$ \\
\hline $\begin{array}{c}\text { Custos com } \\
\text { planejamento e } \\
\text { controle da produção }\end{array}$ & - & $\begin{array}{l}\text { A empresa não realiza o controle sobre esses custos, mas pretende identificar } \\
\text { uma forma de avaliá-los, visto considerar uma atividade importante da } \\
\text { logística. }\end{array}$ \\
\hline Custos de transportes & 72 & $\begin{array}{l}\text { São controlados os valores mais expressivos. Há política formal para o uso } \\
\text { das modalidades de entrega de acordo com o valor de faturamento e } \\
\text { localização do cliente. }\end{array}$ \\
\hline $\begin{array}{l}\text { Custos da logística } \\
\text { reversa }\end{array}$ & - & $\begin{array}{l}\text { Não aplicável para a empresa, visto que não há atividades desse tipo de } \\
\text { logística. }\end{array}$ \\
\hline
\end{tabular}

Fonte: Dados da pesquisa.

Observa-se que, pelo conteúdo do Quadro 8, comparando à literatura, a empresa não identifica alguns custos logísticos de atividades específicas, tais como processamento de pedidos e da tecnologia da informação, planejamento e controle da produção, lotes e custos de armazenagem. Entretanto, destacam-se estas mensuradas, pelo menos parcialmente: embalagem, manutenção de inventário e custos de transportes. O custo de fretes, o mais expressivo, representa aproximadamente $\mathrm{R} \$ 5$ milhões/ano. Conforme já exposto, o controller 
reconhece as limitações atuais na mensuração dos custos logísticos, mas com plano de superálas com o sistema em implantação.

Mesmo sabendo que análises comparativas mais objetivas com outros países precisam de um refinamento de dados e condições operacionais, um paralelo preliminar é possível fazer com dados da pesquisa de Laidens, Teles e Müller (2007), também realizada com empresa do segmento alimentício, os quais identificaram custos de manutenção de estoques e de transporte da ordem de $80 \%$ a $90 \%$, contra $85 \%$ na empresa objeto desta pesquisa. A par das limitações já destacadas, nota-se, nesse aspecto, uma similaridade muito forte entre os parâmetros das duas pesquisas.

Identificou-se, com base nos esclarecimentos do gerente de compras, que a organização já tomou decisões estratégicas sobre os custos logísticos. Os principais fornecedores de matéria-prima estão localizados na região Centro-Oeste do País, onde também há vendas expressivas. Diante disso e da relevância desse custo, decidiu-se construir duas unidades de produção nessa região, cada uma focada nos produtos que atendem à demanda dessa região. O controller acrescentou que, no projeto de avaliação econômica desse investimento, há a projeção de redução de aproximadamente $22 \%$ nos custos com transportes e um aumento de $15 \%$ na lucratividade obtida com os clientes que serão atendidos por essa nova unidade. Isso é particularmente relevante quando se destaca que o custo de transportes corresponde a $72 \%$ do custo logístico total.

Analisadas as informações coletadas, percebe-se que, dadas as limitações existentes, há ainda espaço expressivo para melhorias no controle gerencial dos custos logísticos. De outra parte, observa-se que ações têm sido desenvolvidas para solucionar essa questão.

\subsection{Práticas de Gestão para Análise dos Custos Logísticos}

A análise dos custos logísticos e do seu resultado, mensurados pela margem de ganho, é realizada de diversas formas. Conforme informado pelo controller, a empresa utiliza parcialmente as técnicas de gestão operacional mencionadas pela literatura, no entanto se verifica que ela as trata com outras nomenclaturas. As técnicas de gestão utilizadas, a aplicação realizada, ambas informadas pelo controller, e a nomenclatura identificada na literatura são descritas no Quadro 9.

Importante salientar que o método de custeio utilizado (Contabilidade de Ganhos), apesar de declarado pelo controller que ele atende às necessidades informacionais, diverge em grande escala com o que é indicado pela literatura a qual indica o $A B C$ como o mais adequado para mensuração dos custos logísticos. O consultor acrescentou que essa metodologia, por decisão da empresa, permanecerá no sistema gerencial que está em fase de implantação, ou seja, comparativamente ao que preceitua a literatura a divergência permanecerá.

Quadro 9 - Técnicas de gestão aplicadas pela empresa para análise dos custos logísticos

\begin{tabular}{|c|l|l|}
\hline $\begin{array}{c}\text { Técnica de } \\
\text { gestão aplicada }\end{array}$ & \multicolumn{1}{|c|}{ Aplicação realizada pela empresa } & \multicolumn{1}{|c|}{$\begin{array}{c}\text { Nomenclatura dada } \\
\text { pela literatura }\end{array}$} \\
\hline $\begin{array}{c}\text { Análise por } \\
\text { produto }\end{array}$ & $\begin{array}{l}\text { Rentabilidade de cada produto calculada a partir da receita das } \\
\text { vendas, menos os custos da operação para a fabricação e } \\
\text { distribuição do produto. }\end{array}$ & $\begin{array}{l}\text { Análise da rentabilidade } \\
\text { direta por produto, a } \\
D P P .\end{array}$ \\
\hline $\begin{array}{c}\text { Análise por } \\
\text { pedido }\end{array}$ & $\begin{array}{l}\text { Realizada da mesma forma que a análise por produto, considera } \\
\text { todos os produtos do pedido. Existem produtos não lucrativos, } \\
\text { mas, juntamente com outros de maior margem possibilitam que a } \\
\text { venda seja realizada. }\end{array}$ & $\begin{array}{l}\text { Técnica } \\
\text { denominada por DPP na } \\
\text { literatura, com o foco no } \\
\text { pedido do cliente. }\end{array}$ \\
\hline
\end{tabular}




\begin{tabular}{|c|c|c|}
\hline $\begin{array}{l}\text { Análise por } \\
\text { unidade de } \\
\text { negócio }\end{array}$ & $\begin{array}{l}\text { Para realizar a análise por unidade de negócio, a empresa } \\
\text { preparou a estrutura organizacional. Para identificar quanto cada } \\
\text { unidade agrega valor para a organização como um todo, é } \\
\text { necessário agrupar todos os produtos produzidos pela unidade. } \\
\text { Possibilita analisar qual mix de produtos é mais lucrativo ou até } \\
\text { deficitário. }\end{array}$ & $\begin{array}{l}\text { Prática semelhante a } \\
\text { técnica } D P P \text {, analisando } \\
\text { os produtos agrupados } \\
\text { por unidade de negócio. } \\
\text { Assemelha-se ao } \\
\text { Resultado Divisional. }\end{array}$ \\
\hline $\begin{array}{l}\text { Análise por } \\
\text { cliente }\end{array}$ & $\begin{array}{l}\text { Possibilita visualizar quais são os clientes mais e menos rentáveis. } \\
\text { Identifica todos os custos e receitas geradas por operações } \\
\text { realizadas com um determinado cliente, }\end{array}$ & $\begin{array}{l}\text { A empresa está } \\
\text { utilizando a prática } \\
\text { conhecida como CPA. }\end{array}$ \\
\hline $\begin{array}{l}\text { Análise por } \\
\text { representante }\end{array}$ & $\begin{array}{l}\text { Esta análise é realizada de maneira semelhante à análise por } \\
\text { cliente - da receita de vendas deduzem-se os custos totais } \\
\text { envolvidos em todo processo produtivo, no entanto, neste caso } \\
\text { excluem-se também o valor da comissão pago para o } \\
\text { representante. }\end{array}$ & $\begin{array}{l}\text { A técnica relacionada } \\
\text { nesta análise é o } C P A, \\
\text { porém busca-se } \mathrm{o} \\
\text { representante mais } \\
\text { lucrativo. }\end{array}$ \\
\hline $\begin{array}{l}\text { Análise por } \\
\text { fornecedor }\end{array}$ & $\begin{array}{l}\text { Análise dos custos envolvidos em uma aquisição. Além do preço, } \\
\text { considera-se a qualidade dos produtos, a prestação dos serviços, o } \\
\text { tempo de entrega, os fretes, manutenção e condições de } \\
\text { pagamento. Permite comparar os custos da aquisição do item e } \\
\text { auxilia na seleção de fornecedores. Utiliza o sistema } E D I \text {, auxiliar } \\
\text { na maior rapidez da reposição de materiais e menor custo com } \\
\text { requisições, estoques e manuseio. }\end{array}$ & $\begin{array}{l}\text { Enquadra-se aqui, } \\
\text { mesmo que parcialmente, } \\
\text { a técnica definida na } \\
\text { literatura como TCO. } \\
\text { Também se identifica a } \\
\text { aplicação da ferramenta } \\
\text { de } E D I \text {. }\end{array}$ \\
\hline
\end{tabular}

Fonte: Dados da pesquisa.

O controller esclareceu que a identificação distinta dos custos é possível por que há um plano de contas estruturado que permite o registro separado dos tipos de custos logísticos. Reconheceu, entretanto, que esse sistema ainda funciona parcialmente, o que tem levado àquelas mensurações estimadas citadas anteriormente.

Mesmo com essas limitações, foi possível observar, pelos relatórios apresentados pelo controller, que o controle dentro de cada conta é realizado pelo código do item, tais como embalagem plástica e de madeira. Assim, pelos relatórios financeiros auxiliares é possível visualizar o quanto foi gasto com cada cliente, produto e pedido, e em que tipos de custos. Com a integração do sistema, ainda segundo o controller, essas limitações serão superadas.

Por meio das informações coletadas nos relatórios de custos e em esclarecimentos adicionais do controller, pode-se concluir que a empresa analisada não utiliza as ferramentas de análise dos custos logísticos com a intensidade que indica a literatura relacionada. A recente criação da área de custos explica parcialmente o fato da não aplicação de todas as práticas sobre todos os tipos de custos logísticos.

Assim, com base nas verificações realizadas, apresenta-se, no Quadro 10, a comparação entre a abordagem da literatura e a realidade da empresa com relação à utilização de práticas de gestão e análise dos custos logísticos, apesar de essa nomenclatura não ser de domínio pelos gestores participantes da pesquisa.

Quadro 10 - Grau de utilização das técnicas de gestão

\begin{tabular}{|c|c|c|}
\hline $\begin{array}{c}\text { Técnica citada pela } \\
\text { literatura }\end{array}$ & $\begin{array}{c}\text { Grau de uso ou não } \\
\text { uso pela empresa }\end{array}$ & \multicolumn{1}{|c|}{ Perspectivas de uso ou modificação da aplicação } \\
\hline TCO & Uso parcial & $\begin{array}{l}\text { Aplica basicamente na análise dos fornecedores de serviços } \\
\text { logísticos; não reportou intenção de aplicações diferentes. }\end{array}$ \\
\hline DPP & Utiliza & $\begin{array}{l}\text { Utiliza para análise por unidade de negócio por produto. A } \\
\text { aplicação da técnica pode ser aprimorada caso sejam } \\
\text { incluídos todos os tipos de custos logísticos (conforme } \\
\text { Quadro 3). }\end{array}$ \\
\hline
\end{tabular}




\begin{tabular}{|c|l|l|}
\hline CPA & Utiliza & $\begin{array}{l}\text { Mesmo não utilizando todos os tipos custos logísticos, tem } \\
\text { papel importante nas decisões operacionais da empresa. }\end{array}$ \\
\hline \multirow{3}{*}{ ABC } & Não utiliza & $\begin{array}{l}\text { Não utiliza o método de custeio } A B C \text {; utiliza a Contabilidade } \\
\text { de Ganhos como base para a identificação das informações } \\
\text { de custos. Não há perspectivas de troca de método (para o } \\
A B C), \text { visto que o atual atende as necessidades da empresa. }\end{array}$ \\
\hline \multirow{3}{*}{ ECR } & Uso parcial & $\begin{array}{l}\text { Utiliza-se apenas da ferramenta de EDI para melhoria de } \\
\text { comunicação com alguns fornecedores. Não há projeto de } \\
\text { ampliação da utilização do } E D I \text { ou de outras ferramentas do } \\
E C R .\end{array}$ \\
\hline
\end{tabular}

Fonte: Dados da pesquisa.

O conteúdo do Quadro 10 mostra que, mesmo observadas algumas deficiências da aplicação prática das técnicas de gestão de custos logísticos em relação ao que é indicado pela literatura, é possível verificar aqui maior aplicação do que em outros estudos analisados. Assim, consideradas as limitações já destacadas nos Quadros 8, 9 e 10, pode-se considerar que a empresa adota a gestão de custos logísticos, mesmo que parcialmente. Além disso, a considerar os avanços esperados pela implantação em andamento do sistema integrado de gestão, conforme destacado pelo controller e pelo consultor da empresa, a perspectiva é de que essa gestão tende a ser realizada com mais abrangência e profundidade nas práticas de gestão de custos, inclusive dos originados pelas atividades logísticas.

$\mathrm{Na}$ pesquisa de artigos de congressos e em outros artigos publicados em periódicos científicos, descrita na seção 2.5, nenhum dos estudos empíricos divulgados apresentou casos de aplicação das ferramentas de análises de custos logísticos de forma mais intensiva do que a empresa desta pesquisa. Algumas utilizações pontuais foram localizadas nos diversos estudos citados nos Quadros 4 e 5, apesar de também não haver sinalização de práticas com uso intensivo. São eles: Sievanen, Suomala e Paranko (2004), quanto ao DPP; Guerreiro, Bio e Merschmann (2008), quanto ao CPA; Yanzhong (2012), quanto ao TCO e DPP; Somuyiwa (2010), quanto ao TCO; e Wang, Gao e Lin (2010), quanto ao DPP e CPA.

A respeito da ausência de aplicação mais efetiva do $E C R$, verifica-se consistência com o estudo de Kurnia e Johnston (2001), para os quais as dificuldades de maior evolução no uso da prática se deviam às diversas dificuldades operacionais. Os autores citam como principais restrições à construção de propósitos comuns a confiança mútua, os mútuos benefícios e a divisão equitativa de risco e custos.

Vale destacar que, na última reunião conjunta com todos os quatro entrevistados, em vários momentos, foi necessário proceder a alguns esclarecimentos adicionais sobre a terminologia e significado das práticas de análise dos custos logísticos e pode-se observar o interesse deles pelo conteúdo abordado. Também foi visível o maior domínio desses termos pelo consultor. Isso pode ensejar a necessidade de um treinamento específico para os três gerentes da empresa sobre a temática pesquisada, o que pode contribuir para a aplicação das práticas com mais abrangência, profundidade e em prol da competitividade da empresa.

\section{Considerações Finais}

Por meio deste estudo, procurou-se investigar o uso das práticas de gestão de custos logísticos no âmbito de uma empresa do setor alimentício. Conforme os resultados

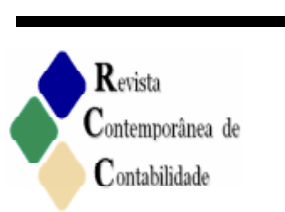


encontrados, pode-se constatar que tais práticas, um tema estratégico na abordagem da literatura, são utilizadas parcialmente na empresa pesquisada.

Mesmo não conhecendo a nomenclatura empregada pela literatura para essas práticas, a empresa utiliza ferramentas que possuem o mesmo objetivo, ainda que de forma parcial, e que suportam o seu processo de tomada de decisão. Apesar de haver lacunas na intensidade prática de aplicação das ferramentas, verifica-se que os custos logísticos são considerados importantes pelos gestores, visto que são alvos de análises estratégicas e operacionais. Observa-se, também, a utilização de um método de custeio para fins gerenciais, a Contabilidade de Ganhos, diferente do método de custeio ABC, o mais indicado pelos estudos científicos pesquisados.

Comparativamente a outros estudos analisados, e apesar da não intensiva utilização das práticas de mensuração e gestão dos custos logísticos, pode-se concluir que a empresa pesquisada apresenta adoção em níveis superiores aos encontrados em outros estudos. Há, ainda, planos para uso com mais abrangência e profundidade dada a perspectiva e andamento de implantação do novo sistema integrado de gestão.

Comparativamente à literatura pesquisada, seja em estudos empíricos, seja em desenvolvimentos teóricos, o que se constata é que a aplicação dos instrumentos de gestão de custos logísticos aqui tratados parecem não encontrar respaldo significativo nas empresas pesquisadas. Apesar de não ser utilizado na empresa pesquisada, há predominância de recomendação para uso do custeio $A B C$.

Dada a falta de confirmação de uso mais intensivo dessas práticas de gestão de custos logísticos, tão destacadas pela literatura, recomendam-se novos estudos objetivamente direcionados a ratificar ou trazer novas informações sobre a utilização práticas desses instrumentos. Acredita-se que tais estudos podem contribuir tanto para motivar o uso das práticas como para validar e/ou reformar alguns dos conceitos apresentados pela literatura.

\section{Referências}

ASSOCIAÇÃO BRASILEIRA DE CUSTOS - ABC. Congresso brasileiro de custos. Disponível em: <http://www.abcustos.org.br/congresso/view?ID_CONGRESSO=21>. Acesso em: 21 nov. 2010.

ASSOCIAÇÃO NACIONAL DE PÓS-GRADUAÇÃO E PESQUISA EM ADMINISTRAÇÃO - ANPAD. Encontros da ANPAD. Disponível em: < http://www.anpad.org.br/eventos.php? cod_evento=1>. Acesso em: 21 nov. 2010.

AVIS, Jo. Performance management: the official CIMA learning system. Oxford: Elsevier, 2009.

BALLOU, Ronald H. Gerenciamento da cadeia de suprimentos/logística empresarial. 5. ed. Porto Alegre: Bookman, 2006a.

BALLOU, Ronald H. The evolution and future of logistics and supply chain management. Produção, v. 16, n. 3, p. 375-386, 2006 b.

BANCO NACIONAL DE DESENVOLVIMENTO ECONÔMICO E SOCIAL - BNDES. Carta Circular n. 10/2010 - Normas relativas ao porte das beneficiárias, março, 2010. 
BOKOR, Zoltán. Integrating logistics cost calculation into production costing. Acta Polytechnica Hungarica, v. 9, n. 3, p. 163-181, 2012.

BOOKBINDER, James H.; ZAROUR, Feyrouz. Direct product profitability and retail shelf space allocation models. Journal of Business Logistics, v. 22, n. 2, p. 183-208, 2001.

BOWERSOX, Donald J.; CLOSS, David. Logistical management. 3. ed. New York: McGraw Hill, 1996.

CAIADO, António C. Pires; AMARO, Sandro Filipe. Aplicação de um modelo de custeio baseado em actividades (ABC) no sector vitivinícola. Revista Contemporânea de Contabilidade, v. 1, n. 5, p. 11-40, jan./jun. 2006.

CAVINATO, Joseph. Total cost/value model for supply chain competitiveness. Journal of Business Logistics, v. 13, n. 2, p. 285-301, 1992.

CHRISTOPHER, Martin. Logística e gerenciamento da cadeia de suprimentos. 2. ed. São Paulo: Cengage Learning, 2007.

CHRISTOPHER, Martin. Logistics and supply-chain management. 4. ed. Upper Saddle River: Prentice Hall, 2010.

COKINS, Gary. Measuring costs across the supply chain. Cost Engineering, v. 43, n. 10, p. 25-31, out. 2001.

COOKE, James A. Costs under pressure. Logistic Management, v. 45, n. 7, p. 34-37, jul. 2006.

DAHER, Cecilio; SILVA, Eldwin; FONSECA, Adelaida. Logística reversa: oportunidade para redução de custos através do gerenciamento da cadeia integrada de valor. BBR Brazilian Business Review, v. 3, n. 1, p. 58-73, jan./jun. 2006.

DAMME, Dick A.V.; ZON, Frank L.A. Activity based costing and decision support. International Journal of Logistics Management, v. 10, n. 1, p. 71-82, 1999.

DENT, Julian. Distribution channels. 2. ed. London: Kogan Page, 2011.

DINITZEN, Henriette B.; BOHLBRO, Dorthe. Value-add logistics in supply management. Copenhagen: Academica, 2010.

EISENHARDT, K. M. Building theories from case study research academy of management. The Academy of Management Review, v. 14, n. 4, p. 532-550, out. 1989.

ELLRAM, Lisa M.; SIFERD, Sue .P. Total cost of ownership: A key concept in strategic cost management decisions. Journal of Business Logistics, v. 19, n. 1, p. 55-84, 1998.

EVERAERT, Patricia; BRUGGEMAN, Werner; SARENS, Gerrit; ANDERSON, Steven R; LEVANT, Yves. Cost modeling in logistics using time-driven ABC: experiences from a wholesaler. International Journal of Physical Distribution \& Logistics Management, v. 38, n. 3, p. 172-191, 2008.

FANG, Yuan; NG, Thomas. Applying activity-based costing approach for construction logistics cost analysis. Construction Innovation, v. 11, n. 3, p. 259-281, 2011. 
FARIA, Ana Cristina; ROBLES, Léo Tadeu. Em busca da vantagem competitiva: trade-offs de custos logísticos em cadeias de suprimento. In: CONGRESSO BRASILEIRO DE CUSTOS, 7, 2000, Recife, PE. Anais... ABCUSTOS, 2000. CD-ROM.

FREIRES, Francisco G. M. Proposta de um modelo de gestão dos custos da cadeia de suprimentos. Dissertação, 2000, 135 f. (Mestrado em Engenharia de Produção), Escola de Engenharia de Produção da Universidade Federal de Santa Catarina, Florianópolis, 2000.

GIL, Antônio Carlos. Métodos e técnicas de pesquisa social. 5. ed. São Paulo: Atlas, 1999.

GONZÁLEZ, Patrícia G. A logística: custo total, processo decisório e tendência futura. Revista de Contabilidade \& Finanças - USP, n. 29, p. 26-40, maio/ago. 2002.

GUERREIRO, Reinaldo; BIO, Sérgio R.; MERSCHMANN, Elvira. Cost-to-serve measurement and customer profitability analysis. International Journal of Logistics Management, v. 19, n. 3, p. 389-407, 2008.

HOFSTETTER, Joerg S.; JONES, Chris Cave. The case for ECR: a review and outlook of continuous ECR implementation in Western Europe. Brussels: ECR Europe, 2006.

HUA, Wang. Status and controlling measures of logistics cost in China's logistic industry. In: WIRELESS COMMUNICATIONS NETWORKING AND MOBILE COMPUTING, 2008. WICON'08 INTERNATIONAL CONFERENCE ON. Dalian, China, 2008. Disponível em: http://ieeexplore.ieee.org/xpl/login.jsp?tp=\&arnumber=4679491\&url=http\%3A\%2F\%2Fieeex plore.ieee.org\%2Fxpls\%2Fabs_all.jsp\%3Farnumber\%3D4679491. Acesso em: 4 out. 2012.

HUTT, Michael D.; SPEH, Thomas W. Business marketing management. 10. ed. Mason $\mathrm{OH}$, South-Western Cencage-Learning, 2009.

INSTITUTO DE LOGÍSTICA E SUPPLY CHAIN - ILOS. Logistics overview in Brazil 2008. Disponível em: http://www.ilos.com.br. Acesso em: 18 nov. 2010.

IUDÍCIBUS, Sérgio. A gestão estratégica de custos e sua interface com a contabilidade gerencial e teoria da contabilidade. RBC, n. 100, p. 30-31, jul./ago. 1996.

KAMINSKI, Luiz A. Proposta de uma sistemática de avaliação dos custos logísticos da distribuição física de uma distribuidora de suprimentos industriais. Dissertação, 2004, $131 \mathrm{f}$. (Mestrado Profissional um Engenharia), Escola de Engenharia da Universidade Federal do Rio Grande do Sul, Porto Alegre, 2004

KAPLAN, Robert; ANDERSON, Steven R. Time-driven activity-based costing. Harvard Business Review, v. 82, n. 11, p. 131-138, nov 2004.

KOPPERS, Laura; KLUMP, Matthias; KÜRBLE, Peter. Value chain management integrating marketing and logistics. In: GRUBBSTRÖM, R. W.; HINTERHUBER, H. H. (Eds). $16^{\text {th }}$ International Working Seminar on Production Economics Conference Proceedings. Innsbruck, March 2010, v. 4, p. 93-104.

KRAJNC, Julijana; LOGOZAR, Klavdij; KOROSEC, Bojana. Activity-based management of logistic costs in a manufacturing company: a case of increased visibility of logistics costs in a Slovenian paper manufacturing company. Traffic \& Transportation, v. 24, n. 1, p. 15-25, 2012. 
KURNIA, Sherah; JOHNSTON, Robert B. Adoption of efficient consumer response: the issue if mutuality. Supply Chain Management: An International Journal, v. 6, n. 5, p. 230-241, 2001.

LAIDENS, Graziela; TELES, Camila D.; MÜLLER, Cláudio J. Avaliação dos custos logísticos em empresas do setor alimentício. Estudos tecnológicos, v. 3, n. 2, p. 83-91, 2007.

LAKATOS, Eva Maria; MARCONI, Marina de Andrade. Técnicas de pesquisa. 4. ed. São Paulo: Atlas, 1999.

LALONDE, Bernard; POHLEN, Terrance. Issues in supply chain costing. The International Journal of Logistics Management, v. 7, n. 1, p. 1-12, 1996.

LAMBERT, D.M.; STOCK, J.R. Strategic logistics management. 4. ed. New York: Irwin McGraw-Hill, 2001.

LIMA, Maurício Pimenta. Custos logísticos: uma visão gerencial. In: FLEURY, Paulo Fernando; WANKE, Peter; FUGUEIREDO, Kleber Fossati. Logística Empresarial. São Paulo: Atlas, 2000, p. 250-283.

MINTZBERG, Henry; LAMPEL, Joseph; QUINN, James B.; GHOSHAL, Sumantra: o processo da estratégia. 4. ed. Porto Alegre: Bookman, 2006.

MITTAL, V.; SARKEES, M.; MURSHED, F. The right way to unprofitable customers. Harvard Business Review, v. 86, n. 4, p. 95-102, abr. 2008.

PAIVA, Ely L.; CARVALHO JR.; José M.; FENSTERSEIFER, Jaime E. Estratégia de produção e de operações. 2. ed. Porto Alegre: Bookman, 2009.

PORTER, M. E. Vantagem competitiva. Rio de Janeiro: Campus, 1989.

QUEIROZ, Antônio D.; COSTA, Renato; GOMES, Sônia Maria S. O ABC em uma empresa de desenvolvimento de software: um estudo de caso. Revista Contemporânea de Contabilidade, v. 1, n. 1, p. 29-44, jan./jun. 2004.

ROBLES JR, Antonio; ROBLES, Léo Tadeu; FARIA, Ana Cristina de. Custos para servir: uma proposta de aplicação para uma empresa de tintas. Revista Universo Contábil, v. 1, n. 1, p. 71-85, 2005.

RUSSEL, Stephen H. Supply chain management: more than integrated logistics. Air Force Journal of Logistics, v. 31, n. 2, p. 56-63, 2007.

SAHA, Sonali K; CORLEY, Kevin G. Building better theory by bridging the quatitativequalitative divide. Journal of Management Studies, v. 43, n. 8, p. 1821-1835, Dec. 2006.

SIEVANEN, Matti; SUOMALA, Petri; PARANKO, Jari. Product profitability: causes and effects. Industrial Marketing Management, v. 33, n. 5, p. 393-401, jul. 2004.

SILVA, Liane F. S; VILLAR, Antônio M. Discussão sobre as técnicas de avaliação dos custos logísticos para fins de controle gerencial. In: CONGRESSO BRASILEIRO DE CUSTOS, 14, 2007, João Pessoa - PB. Anais: ABCUSTOS, 2007, CD-ROM.

SKINNER, Wickham. Manufacturing - missing link in corporate strategy. Harvard Business Review, v. 47, n. 3, p. 136-145, maio/jun. 1969. 
SOMUYIWA, Adebambo O. Modeling outbound logistics costs measurement system of manufacturing companies in Southwestern, Nigeria. European Journal of Social Sciences, v. 15, n. 3, p. 382-395, 2010.

SOUZA, Fernando B.; PIRES, Silvio R.I. Theory of constraints contributions to outbound logistics. Management Research Review, v. 33, n. 7, p. 683-700, 2010.

SOUZA, Marcos A; COLLAZIOL, Elisandra; KIRCH, Guilherme. Gestão econômica de sistemas logísticos: uma investigação sobre o uso de técnicas de mensuração. In: SIMPEP, 11, 2004, Bauru - SP. Anais... UNESP, 2004, CD-ROM

SOUZA, Marcos A.; CORREA, Rodrigo M.; KRUGER, Gustavo P.; KRONBAUER, Clóvis A. Custos Logísticos: mensuração e uso por redes supermercadistas do estado do Rio Grande do Sul. In: Encontro da Anpad - EnANPAD, 34., 2010, Rio de Janeiro. Anais... ANPAD, 2010.

SOUZA, Marcos A.; DIEHL, Carlos A. Gestão de custos: uma abordagem integrada entre contabilidade, engenharia e administração. São Paulo: Atlas, 2009.

SOUZA, Paulo T. Logística interna: modelo de reposição semiautomático de materiais e suprimentos. 2002. 104 f. Dissertação (Mestrado em Engenharia de Produção) - Curso de Pós Graduação em Engenharia de Produção, Faculade de Engenharia de Produção da Universidade Federal de Santa Catarina, Florianópolis, 2002.

UNIVERSIDADE DE SÃO PAULO - USP, Faculdade de Economia, Administração e Contabilidade. Congressos USP de Controladoria e Contabilidade. Disponível em: http://www.congressousp.fipecafi.org/>. Acesso em: 05 nov. 2010.

VASCONCELLOS, Themis C.; MARINS, Fernando A. S.; MUNIZ JUNIOR, Jorge. Implantação do método activity costing na logística interna de uma empresa química. Gestão \& Produção, v. 15, n. 2, p. 323-335, 2008.

VODENICHAROVA, Maria. Cluster analysis of Bulgarian meat processing industry. Research in Logistic \& Production, v. 1, n. 3, p. 163-173. 2011.

WANG, Geng; GAO, Zhongming; LIN, Thomas. Using ABC to improve the logistics value chain in a Chinese food product company. Cost Management, v. 24, n. 1, p. 39-46, 2010.

WANK, Bo; LI, Xiram. Value-based enterprise logistics cost management mode. School of Economics and Management, Heilongjiang Institute of Science And Technology, P.R. China. p. 483-488, 2010. Disponível em: http://www.seiofbluemountain.com/upload/product/201002/1265267838lnb1ja9g.pdf. Acesso em: 04 abr. 2011.

WHEELWRIGHT, Steven. Manufacturing strategy: defining the missing link. Strategic Management Journal, v. 5, n. 1, p. 77-91, 1984.

WOOD JR., Thomaz; ZUFFO, Paulo K. Supply chain management. RAE - Revista de Administração de Empresas, v. 38, n. 3, p. 55-63, jul./set. 1998.

YANZHONG, Gou. Logistics cost management in emerging market: evidence from China. School of Business \& Economic Management, Xinjiang University of Finance. 2009. Disponível em: www.seiofbluemountain.cpm/search/detail.php?id=4454. Acesso em: 28 set. 2012. 
YIN, Robert K. Estudo de caso: planejamento e métodos. Porto Alegre: Bookman, 2001.

ZANQUETTO FILHO, Hélio; PIZZOLATO, Nédio D. Desempenho na cadeia logística: ênfase no sistema de custeio. In: ENEGEP, 20, 2000, São Paulo. Anais... ABEPRO, 2000. CD-ROM.

ZHAO, Xiaofeng; TANG Qi. Analysis and strategy of the Chinese logistics cost reduction. International Journal of Business and Management, v. 4, n. 4, p. 188-191, 2009 